\title{
Evaluation of Regional Climatic Model Simulated Aerosol Optical Properties over South Africa Using Ground-Based and Satellite Observations
}

\author{
M. Tesfaye, ${ }^{1,2}$ J. Botai, $^{1}$ V. Sivakumar, ${ }^{1,3}$ and G. Mengistu Tsidu ${ }^{4}$ \\ ${ }^{1}$ Department of Geography, Geoinformatics and Meteorology, University of Pretoria, Lynwood Road, Pretoria 0002, South Africa \\ ${ }^{2}$ National Laser Centre, Council for Scientific and Industrial Research, P.O. Box 395, Pretoria 0001, South Africa \\ ${ }^{3}$ Discipline of Physics, School of Chemistry and Physics, University of KwaZulu Natal, Westville, Durban 4000, South Africa \\ ${ }^{4}$ Department of Physics, Addis Ababa University, P.O. Box 1176, Addis Ababa, Ethiopia
}

Correspondence should be addressed to M. Tesfaye; mela_20062@yahoo.com

Received 21 August 2013; Accepted 13 September 2013

Academic Editors: G. A. Gerosa and K. Schaefer

Copyright (c) 2013 M. Tesfaye et al. This is an open access article distributed under the Creative Commons Attribution License, which permits unrestricted use, distribution, and reproduction in any medium, provided the original work is properly cited.

\begin{abstract}
The present study evaluates the aerosol optical property computing performance of the Regional Climate Model (RegCM4) which is interactively coupled with anthropogenic-desert dust schemes, in South Africa. The validation was carried out by comparing RegCM4 estimated: aerosol extinction coefficient profile, Aerosol Optical Depth (AOD), and Single Scattering Albedo (SSA) with AERONET, LIDAR, and MISR observations. The results showed that the magnitudes of simulated AOD at the Skukuza station $\left(24^{\circ} \mathrm{S}, 31^{\circ} \mathrm{E}\right)$ are within the standard deviation of AERONET and $\pm 25 \%$ of MISR observations. Within the latitudinal range of $26.5^{\circ} \mathrm{S}$ to $24.5^{\circ} \mathrm{S}$, simulated AOD and SSA values are within the standard deviation of MISR retrievals. However, within the latitude range of $33.5^{\circ} \mathrm{S}$ to $27^{\circ} \mathrm{S}$, the model exhibited enhanced AOD and SSA values when compared with MISR observations. This is primarily associated with the dry bias in simulated precipitation that leads to the overestimation of dust emission and underestimation of aerosol wet deposition. With respect to LIDAR, the model performed well in capturing the major aerosol extinction profiles. Overall, the results showed that RegCM4 has a good ability in reproducing the major observational features of aerosol optical fields over the area of interest.
\end{abstract}

\section{Introduction}

Atmospheric aerosols which originate from different natural events (e.g., wind-blown dust and sea salt particles) and human activities such as combustion of biomass and fossil fuels, as well as various industrial processes (e.g., sulfates, nitrates, ammonium, and carbonaceous aerosols) are ubiquitous in the Earth's atmosphere [1]. Relative to the well mixed and long-lived greenhouse gases, one of the main typical properties of atmospheric aerosols is their immense diversity, not only with respect to their physicochemical and optical properties, but also with regards to their spatial and temporal distributions (e.g., [2]). This is attributed to their diverse local source mechanisms, rapid aging, and chemical transformation processes, as well as short lifetime [3]. Though, owing to these heterogeneous properties of aerosols, the quantification of their climatic roles remains with large uncertainties; they are increasingly reported as one of the crucial components of the atmosphere for multiclimatic issues ([4] and references therein).

Primarily, atmospheric aerosols play an important role in modulating the regional radiation budget either through scattering or absorption of radiation (direct effects) (e.g., [5]). The perturbation of the radiation balance of the Earth through scattering of the incoming solar radiation back to space cools the Earth's surface as well as certain portions of the troposphere, but it induces stratospheric warming (e.g., [6]). The absorption of short and long wave radiation predominantly prompts atmospheric heating effects; nevertheless, depending on the underlying surface as well as the atmospheric situations, it might also result to surface cooling (e.g., $[7,8]$ and references therein). Particulates that 
are highly absorbing solar radiation such as black carbon and mineral dust particles have a substantial influence in converting the solar energy into heat; this radiative heating in turn creates the semidirect effect of aerosols. The semidirect effect is the response of thermal, hydrological, and dynamical variables of the climate to atmospheric heating induced by light-absorbing aerosols (e.g., [7, 9]). For instance, the warming influence of aerosols in lower troposphere often enhances the low-level cloud evaporation and atmospheric stability, which consecutively results in the reduction of cloudiness as well as the slowing of the hydrological cycle and the suppression of convection processes (e.g., [1, 914]). Additionally, the strong heating effects of absorbing aerosols in the lower troposphere will produce alterations in atmospheric circulation (e.g., [14, 15]). Furthermore, as discussed by different studies, depending on the relative position of the absorbing aerosol layer with respect to clouds (e.g., $[13,16-18])$ as well as the underlying surface properties $[19,20]$, the semidirect effect may also result in instability of the atmosphere and an increase in cloud water.

In general, attributed to the involvement of various atmospheric, surface, and other variables, the computation of semi-direct effects of aerosols is quite complicated and highly variable $[19,20]$. Moreover, aerosols enhance the cloud number droplets and decrease its mean droplet size by acting as cloud condensation nuclei. This results in the change in cloud albedo and radiative properties, reducing precipitation efficiency which might influence the cloud lifetime as well as its formation processes and coverage (indirect effects) ([21-23] and references therein). Likewise, different reports point to the involvement of atmospheric aerosols in several climatic system topics: in a range of tropospheric chemistry variations [24], stratospheric ozone depletion [25], and in several ecological concerns (e.g., [26-28]).

Once aerosols are released into (formed in) the atmosphere, they will be transported to fields far away from the areas of their origin. However, during their transportation they will be subjected to numerous physicochemical transformations and removal processes such as dry and wet deposition and gravitational settling [29-31]. Thus, as aerosols travel further away from their source regions, their concentration and impact will decline drastically $[3,32]$. As a result of this declination, the impact of aerosols on climate must be understood and quantified on a regional scale (i.e., in and around their source regions) rather than on a global-average basis (e.g., $[1,33,34])$. Due to the extreme heterogeneity of aerosol space-time distribution, as well as physicochemical properties, the quantitative assessments of certain puzzling climatic roles and different aspects of aerosols through observations (field experiments) are prohibitively expensive and highly constrained by various factors (e.g., [4, 35-39]).

Therefore, studying the climatic effects of aerosols using chemistry/aerosol models which are radiatively active and coupled with the meteorological models with online feedback on the radiation and climatic schemes (e.g., [40-45]) is crucial. In addition, models are also indispensable tools for estimating the past and projecting the future climatic role of aerosol forcing (e.g., [46, 47]). Since the late 1980s, interactively coupled climate-aerosol models for global scale (e.g.,
$[48,49]$ and references therein) and regional scale ([50] and references therein) simulations have been developed. Global and regional models are now becoming more complex as they incorporate new parameterizations of aerosol properties and processes. Global-scale models, due to their frequently implemented coarse grid resolution, do not accurately simulate the regional-scale spatiotemporal distributions of atmospheric aerosols, as well as meteorological processes that govern the aerosol-atmosphere-radiation-chemistry interactions (e.g., $[30,51-54])$. As a result of this and other aspects, predictions of aerosol optical properties and climatic forcings employing global-scale models are exposed to remarkable uncertainties (e.g., $[8,30,53,55-58]$ and references therein).

On the other hand, the high-resolution climatic system (i.e., the surface, ocean as well as atmospheric processes) representations of Regional Climate Models (RCMs) offer enhanced advantages in assessing the downscaled meteorological processes as well as different climatic information and patterns (e.g., [59-61] and references therein). Furthermore, interactively coupled high-resolution regional climate-chemistry/aerosol models progressively turn out to be a suitable tool in assessing the regional scale distribution and complex climatic roles of aerosols with a much better computational cost, relative to global climatic models (e.g., [29, 62-69]). In addition, the results from high-resolution RCMs are well suited for comparison with measurements of individual events at selected sites/areas. Therefore, to evaluate the regional scale aerosol distributions, along with their radiative and climatic impact with improved accuracy, simulations utilizing high resolution RCMs are vital (e.g., $[29,69])$.

The literature on aerosol studies employing the art of RCM over Africa is not exhaustive. Most studies which have been reported over this continent such as Solmon et al. [67], Konare et al. [70], and Malavelle et al. [71] have focused on the effect of mineral dust and biomass burning particles over the West African regions. On the other hand, South Africa, which has plenty of industries and mining sectors, is the most industrialized country in the continent. These human activities, along with the wide usage of coal for electricity generation, make South Africa one of the remarkable spots in the globe, which contributes several types of aerosols via anthropogenic activities (e.g., [72-75]). Further, many spaceand ground-based observational studies (e.g., [2, 76-80] and references therein) and modeling studies $([69,80,81]$ and references therein) identify South Africa as a major source of anthropogenic aerosols in the subcontinent. Different intensive field-campaign observations such as Southern African Regional Science Initiative (SAFARI) (e.g., [82-84]) and aerosol climatology studies (e.g., $[2,85]$ ) indicate that during the dry seasons, South Africa experiences a drastic burden of aerosols from biomass burning activities. In addition, the dust blowing from the arid/semiarid regions of South Africa and its neighboring countries $[2,76,86]$, along with marine aerosols-which are induced from the surrounding oceans $[2,85]$ - is another main component of natural aerosols over South Africa.

In overall, due to various natural/anthropogenic events, the South African atmosphere is burdened by almost all 
major types of aerosols. As aforementioned, the impact of aerosols is considerably substantial near to their source regions; therefore, the regional scale distributions as well as climatic impact of aerosols-which are induced in and around South African regions-need to be assessed and reported separately. To date, only a single study has been reported employing interactively coupled regional climatechemistry/aerosol model (ICTP RegCM4-aerosol model) over southern Africa [69]. This study focused on the direct and semidirect radiative effects of biomass burning and dust aerosols on southern Africa's regional climate during the dry winter season only. A study devoted to compressively examine the seasonal distributions and long-term climatic signals of individual/combined aerosol components using the above model over South Africa is still lacking. Therefore, using the ICTP RegCM4-aerosol model [50], studies that follow this paper and are reported elsewhere will compressively examine the seasonal distributions, as well as the direct and semi-direct effects of different components of aerosols over South Africa. However, before employing the model for the investigation of atmospheric aerosol radiative and climatic effects, its performance in computing the magnitudes as well as the spatiotemporal evolution of the optical properties of aerosols needs to be evaluated via comparing with a range of remote sensing/in-situ observations.

Modeling the direct influence of aerosols on the earth's radiation balance by solving the radiative transfer equation needs the following spectral aerosol optical parameters: (a) aerosol extinction optical depth (AOD), (b) asymmetry parameter, and (c) single scattering albedo (SSA) (e.g., [5, 29]). These optical parameters are significantly dependent on the aerosol's composition (complex refractive index), particle size (particle size distribution), shape, wavelength, and relative humidity [87-90]. AOD is the vertical integral of fraction of solar/terrestrial radiation either scattered or absorbed by airborne particles (i.e., the sum of aerosol scattering and absorption optical depths) (e.g., [87]). The asymmetry parameter is the intensity-weighted mean value of the cosine of the scattering angle (e.g., [91]); it determines the net angular distribution of aerosol scattered light. The SSA (i.e., the ratio of the extinction due to scattering to the total extinction due to scattering plus absorption) is an important parameter that governs the relative efficiency of particles to scatter solar/thermal radiation compared to absorption (e.g., [92]). Depending on the underlying surface albedo, these optical properties of aerosols are the key parameters driving the magnitude, as well as a sign of aerosol direct radiative forcing (i.e., in driving the aerosol radiative cooling/heating roles) (e.g., [7, 93]). Therefore, to understand and evaluate various aspects of atmospheric aerosols, a reasonable quantification of these optical parameters is crucial. Additionally, these aerosol optical properties are the most comprehensive standard quantities that link the observations with the outcomes of the model.

Concerning aerosol microphysical and optical property inquiries, field measurements provide more detailed information with better accuracies (e.g., [87, 94]); however, they are confined within temporal or spatial coverage (e.g., [95]). Satellite observations provide the requisite aerosol optical property distributions with extensive temporal and spatial coverage (e.g., [95]). Nonetheless, due to high variability of the earth's system reflectance, both in space and time, as well as aerosol physicochemical properties, satellite retrievals are exposed to some accuracy limitations and constraints to deliver some essential aerosol quantities such as aerosol compositions [37, 38, 96-100]. As a result, neither field measurements nor satellite observations, alone, would be sufficient to fully describe the total regional scale aerosol distributions as well as its physical, chemical, and optical properties. Alternatively, interactively coupled regional climatechemistry/aerosol models (RC-aerosol models), which comprises a suite of major atmospheric aerosols, with their detailed parameterizations, are essential in delivering various parameters which are related to aerosols and their climatic roles, with high-temporal and spatial resolutions. To this end, the RC-aerosol models have a capability of providing important information about the complex aerosolsradiation-climatic interactions and the physicochemical production/transformation rate of particles as well as their concentration and optical parameters. Some of this information gained from modeling studies cannot be easily addressed from either satellite retrievals or field measurements.

Notwithstanding the contribution of RC-aerosol models, modeling the entire complex aerosol processes (i.e., emission, transportation, physicochemical transformation, and removal, as well as wavelength and climatic condition dependent aerosol optical properties) is fundamentally a challenging task [29]. Further, errors in simulated meteorological fields, insufficiently understood physico-chemical processes of aerosols, inaccurately estimated precursor-gas/particulate emissions by the inventories used (e.g., [101]), and many other factors will impose significant uncertainties in simulating optical characteristics of aerosols [30, 34, 57]. The inaccuracies in model estimated optical parameters of aerosols will also propagate a substantial uncertainty on the computation of aerosol's direct radiative forcing and its consequential semidirect influences (e.g., [4, 34]). Thus, to compensate the deficiencies of one technique via another and to reduce inaccuracies in model predicted optical properties of aerosols, an hybrid research effort that integrates observational records and numerical modeling techniques is essential (e.g., [40, 81, 95, 102-105]).

The present study will evaluate the ICTP RegCM4aerosol model capability of simulating the magnitude as well as the spatiotemporal evolution of optical properties of aerosols via comparing with different field observations, in South Africa. Such studies would also contribute important role to pointing-out the shortcomings of the model's parameterizations (e.g., [29]). In this study, including different types of aerosols which is induced from natural processes and distinct emission sectors in and around South Africa (see our simulation domain in Figure 1), a longterm regional climate/aerosol simulation has been carried out using RegCM4-aerosol model (see Sections 2.2 and 2.4). To estimate particulates/precursor-gases which are emitted from different anthropogenic/biomass burning sectors, recently updated emission inventories have been used (see Section 2.3). Subsequent to these, the evaluation of simulated 


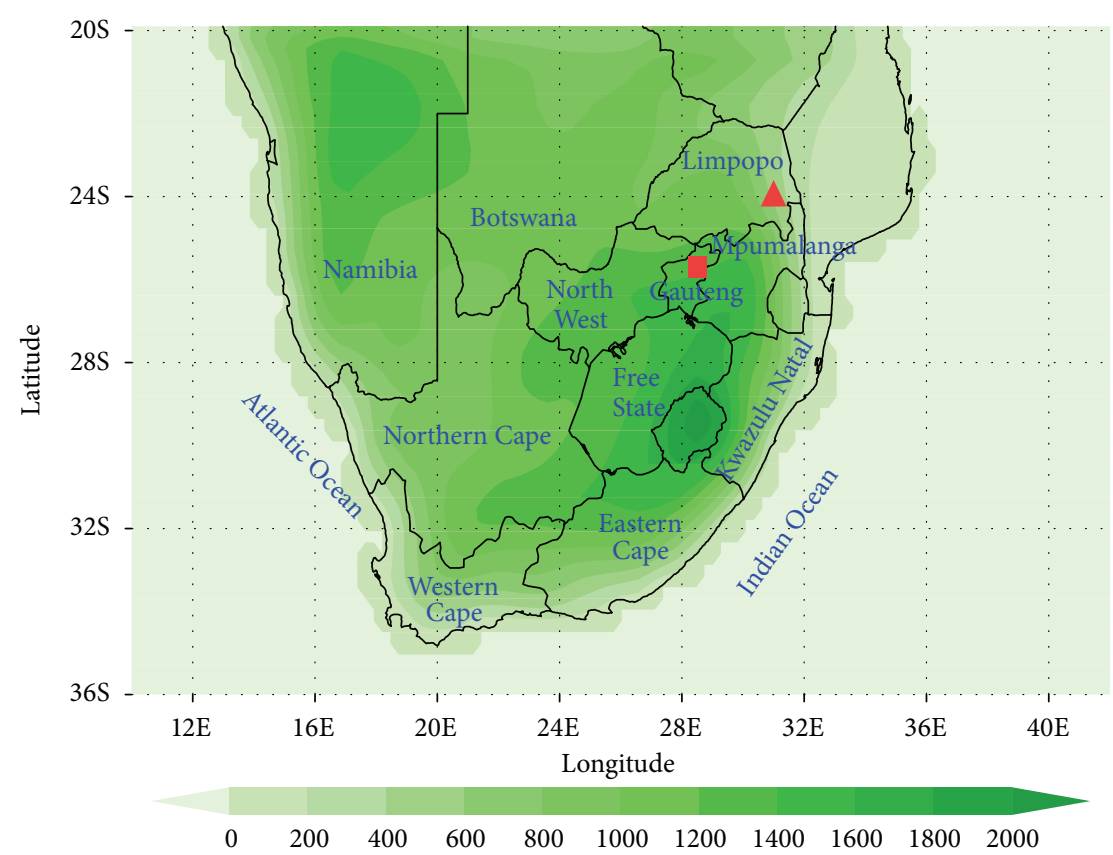

FIGURE 1: Model domain and topography (unit: $\mathrm{m}$ ). The red triangle and square, respectively, indicate the geographical location of AERONET (Skukuza; $24^{\circ} \mathrm{S}, 31^{\circ} \mathrm{E}$ ) and LIDAR (University of Pretoria; $25.7^{\circ} \mathrm{S} ; 28.2^{\circ} \mathrm{E}$ ) surface observation sites.

aerosol optical fields over South Africa $\left(22^{\circ} \mathrm{S}\right.$ to $34^{\circ} \mathrm{S}$ and $16^{\circ} \mathrm{E}$ to $32^{\circ} \mathrm{E}$ (see Figure 1$)$ ) has been carried out by comparing with values obtained from ground (sun-photometer and LIDAR) and spaceborne (MISR) observations. The paper is organized as follows. Section 2 will provide a brief description about the ICTP RegCM4-aerosol model along with the employed model physics parameterization, emission inventories used in the model, and the experimental design. In addition, the different surface/satellite products used for evaluating model outputs will be addressed in this section. In Section 3, comparing with different remote sensing products, we present the evaluation of the model's performance in simulating the magnitude and spatio-temporal evolution of column integrated aerosol optical properties, as well as their vertical distribution. Along with the validation, different rationale aspects which might be accountable for the biases of the simulated aerosol optical fields are discussed. A summary, concluding remarks, and future perspectives are given in Section 4 .

\section{Methodology}

2.1. Model Description. In this study, for the regional climate/aerosol simulation, interactively coupled regional climate-aerosol model is used. The climate component of the coupled model is the Regional Climate Model (RegCM) version 4.0 (RegCM4.0), developed at the International Centre for Theoretical Physics (ICTP). RegCM4 is a hydrostatic, compressible, sigma vertical coordinate model, which is an upgraded version of RegCM3 with the similar basic model dynamics but with certain improvements in various physics representations and software code [50]. For a more detailed description of RegCM and its substantial evolution starting from the first generation (RegCM1; $[106])$ to the current version, the reader is referred to $([50,61]$ and references therein).

Among different model physics parameterization schemes of RegCM4, this study employs the following scheme: for the radiative transfer computation-the Community Climate Model-CCM3 radiative transfer package [107] is used. This radiative transfer package takes into account the radiative effect of different greenhouse gases, atmospheric aerosols and cloud water-ice, in different spectral bands. The radiative flux calculations include 18 spectral intervals which are within a wavelength range of 0.2 to $4.5 \mu \mathrm{m}$. Among these 18 spectral bands, seven of them are situated in the ultraviolet spectral interval $(0.2-0.35 \mu \mathrm{m})$, one is in the visible band $(0.35-0.64 \mu \mathrm{m})$ and the remaining spectral bands cover the infrared/special absorption windows [107]. The ocean surface fluxes are computed according to the scheme of Zeng et al. [108], and the land surface physics, which describe the transfer of energy, mass, and momentum between the atmosphere and the biosphere, is described by the biosphere-atmosphere transfer scheme (BATS; $[109,110])$. The planetary boundary layer processes are characterized according to the nonlocal parameterization of Holtslag et al. [111]. The convective precipitation is represented by the mass flux scheme of Grell [112] with the Fritsch and Chappell [113] closure assumption, while the large-scale cloud and non-convective precipitation computations follow the Sub-grid explicit moisture scheme (SUBEX) of Pal et al. [114].

2.2. RegCM4-Aerosol Model. The RegCM4-aerosol model is interactively coupled model between RegCM4 and radiatively active simplified anthropogenic and dust aerosol models, which can be used to examine the two-way 
aerosol-climate feedback [50]. The RegCM4-aerosol model allows the simulation of major tropospheric aerosols, which originate from anthropogenic and biomass burning activities [29], as well as wind eroded desert dust particles $[63,67]$. The anthropogenic and biomass burning aerosol schemes account for sulfur dioxide $\left(\mathrm{SO}_{2}\right)$, sulfate $\left(\mathrm{SO}_{4}{ }^{-2}\right)$, hydrophobic and hydrophilic components of black carbon (BC), and organic carbon (OC) particles [29]. Following Qian et al. [42] the model takes into account the chemical conversion of $\mathrm{SO}_{2}$ to $\mathrm{SO}_{4}{ }^{-2}$ through both gaseous-phase and aqueous-phase pathways.

The atmospheric processes of these aerosols: surface emission, transportation (via advection by atmospheric winds, turbulent diffusion and deep convection), physicochemical transformations, and removal processes (via wet and dry depositions) are described by the tracer transport equation of Solmon et al. [29]. The essential steps and mechanisms which are considered for developing and implementing the online dynamical dust production scheme, together with the parameterizations of several factors which influence the dust emission processes, are described in detail by Zakey et al. [63]. The dust scheme of RegCM4 represents the dry dust particle size distribution through size bin approach. The whole-size spectrum of dust particles covers a diameter range of 0.01 to $20.0 \mu \mathrm{m}$, divided into 4 size-bins, that is, the fine $(0.01-1.0 \mu \mathrm{m})$, accumulation $(1.0-2.5 \mu \mathrm{m})$, coarse $(2.5-$ $5.0 \mu \mathrm{m})$, and giant $(5.0-20.0 \mu \mathrm{m})$ particle size modes [63]. As described in Zakey et al. [63], during the inclusion of dust module in RegCM framework, some new parameterizations of the dustatmospheric process (such as, size-dependent gravitational settling processes of dust particles) are incorporated into the tracer transport equation of Solmon et al. [29].

For each wavelength of the RegCM4 radiation scheme and for each aerosol species, the aerosol size distribution and refractive index dependent optical properties (i.e., asymmetry factor, single scattering albedo, and mass extinction coefficient) are computed using the Mie theory and employed in the model [29]. Using prognostic dust bin concentrations, long-wave refractive indices, and absorption cross sections, the dust particles long-wave emissivity/absorptivity influences are implemented based on Solmon et al. [67]. The relative humidity influences on optical properties of hydrophilic aerosols are specified according to Solmon et al. [29]. Accordingly, the model computes the shortwave radiative influences of all the above aerosol types using these optical properties, along with the long-wave effects of dust particles [50]. More information on different aspects of RegCM4-aerosol model is described in Giorgi et al. [50]. Over the years, this model has been widely used to examine the regional-scale direct radiative forcing of aerosols and their climatic effects in different parts of the globe (e.g., [43, 67, 69-71, 115-117]). In this study, also employing two recently updated emission inventories in the model (which are described in Section 2.3), a long term regional climate/aerosol simulation has been carried out.

Before we carry on to the next section, we would like to highlight some of the limitations which are associated with our simulation, as well as the aerosol schemes of RegCM4. This, further than assisting this study, it will also avoid the repetition of information in studies that follow this contribution [118-121]. Most of the earlier studies, for example, several studies reported in IPCC [4] clearly stated the importance of the indirect effects of aerosols along with its current uncertainties. Nonetheless, one of the main caveats of RegCM4-aerosol model is that it does not include this aerosol effect. The next limitation is associated with the assumption used regarding the complex mixing state of the particles. Throughout our studies, the external mixing assumption is used for the computation of the total optical parameters of aerosols. This is based on previous studies which reported that nearby the aerosol source region, the extinction cross section is slightly sensitive to the mixing hypothesis (e.g., [93, 122]). However, there are several processes in the atmosphere that will alter an external mixture of particles into an internal mixture (e.g., [123]). In fact, different studies show a high sensitivity of the bulk aerosol optical and microphysical properties as well as its radiative and climatic influences to the aerosol mixing state assumptions (e.g., [41, 124-128]). Accordingly, the effort of understanding the internal/external mixture assumptions, along with their consequential aspects (via modifying the RegCM4-aerosol model parameterizations), is currently in progress [129], while the sea salt particles contribution is primarily noted only within limited coastal areas of South Africa, following the rise of southeasterly wind speed for a short period of time (e.g., [2]). Thus, for meanwhile our simulations do not encompass marine aerosols. Additionally, the simulation does not take into account the long-wave effects of carbonaceous and sulfate particles. In fact, the particle interaction with thermal infrared radiation is significant if the aerosols are large in size such as for dust and sea salt particles. For smaller aerosols, the extinction coefficient decreases rapidly with increasing wavelength (e.g., $[90,130])$. Therefore, omitting the longwave radiation effects of carbonaceous and sulfate particles will not impose a significant error in long-wave radiation computation, as well as in assessing the direct and semi-direct effects of these particles.

2.3. Emission Datasets. In this study, the emission estimates of black carbon (BC) and organic carbon (OC) particles, and sulfur dioxide $\left(\mathrm{SO}_{2}\right)$ which are induced from anthropogenic and biomass burning activities are derived from two recently updated emission inventories: MACCity [131] and Global Fire Emissions Database, version 3 (GFED3) [132], respectively. Both inventories are provided at spatial resolution of $0.5 \times 0.5$ degree over the globe with a monthly temporal resolution. The MACCity inventory is the upgraded extension of ACCMIP (Atmospheric Chemistry and Climate-Model Intercomparison Project) emissions dataset [131]. Covering a period from 1990 to 2010, this emission database provides various gases and aerosol species, which are contributed from different anthropogenic sectors such as power plant, industrial activities, and transportations. The GFED3 inventory applies global scale satellite-derived products such as vegetation characteristics, productivity, and burned area estimates, along with a fire module of a biogeochemical model, as well as several conditions to estimate emissions 
from biomass burning activities (i.e., from grass, peat, woodland, forest, open savanna, deforestation fires, and agricultural waste burnings; see Giglio et al. [133] and van der Werf et al. [132, 134]. Further details of GFED3 approaches and spatio-temporal emission variability are compressively described in van der Werf et al. [132] and references therein. This dataset contains several trace gases and particulate matter which emitted from these open biomass burning activities, for the period from 1997 to 2009.

2.4. Experimental Design. For the purpose of evaluating the coupled model's (i.e., RegCM4-aerosol model) capability of simulating the total atmospheric aerosol optical parameters, as well as extracting the aerosol-induced climate-impact signal from the underlying noise, a long term simulation is essential. Implementing the above recently updated emission inventories we have conducted a series of simulations, which extends from January 1997 to December 2008 and analyses the recent 11 years' results. To eliminate boundary effects (e.g., $[135,136])$, the simulation domain is designed to be larger than the area of interest; that is, our simulation domain (from $5.5^{\circ} \mathrm{E}$ to $47.1^{\circ} \mathrm{E}$ and from $37.5^{\circ} \mathrm{S}$ to $18.6^{\circ} \mathrm{S}$ ) encompasses the entire South Africa and its surrounding land/ocean regions (Figure 1) at a horizontal grid resolution of $60 \mathrm{~km}$ with 18 vertical layers. Though, the finest horizontal resolution of RegCM4 can be set to $10 \mathrm{~km}$; considering our domain size, the horizontal spacing used in this study is fairly adequate to make a multiyear simulation with a reasonable computational time. Taking into account the aerosol influence on radiation, as well as the two-way aerosol-climate feedbacks, all the ten tracers available in RegCM4 are included in our simulation under external mixture assumption. The European Centre for Medium-Range Weather Forecasts (ECMWF) reanalysis ERA interim (ERAIN: $[137,138]$ ) and the weekly mean product of National Ocean and Atmosphere Administration's (NOAA) Optimum Interpolated sea surface temperature (OISST) [139] are implemented for limited-area model that required time-dependent initial and lateral boundary conditions. The simulations presented here use a time setup of 10 minutes for surface parameter files (topography, land use, vegetation, soil type, etc.), along with the dynamical model time step of 150 seconds and 6 hours updating lateral boundary conditions. Most of the model's climatic schemes, as well as meteorological lateral boundary condition selections, are based on Tummon [80] sensitivity and performance studies of RegCM schemes over Southern Africa. Since this work is the first step towards applying the RegCM4-aerosol model for the investigation of radiative and climatic effects of different types of aerosol over South Africa, we have tested and discussed the model's performance in terms of computing different optical fields of aerosols over this region only.

\subsection{Observational Data}

2.5.1. AERONET Surface Observation. The Aerosol Robotic Network (AERONET) is a global ground-based network of automated sun-photometer measurements [140]. AERONET provides aerosol optical depth and surface solar flux, as well as employing improved retrieval algorithms; it delivers different sets of atmospheric column aerosol optical and microphysical parameters (e.g., [141]). Even if there are different AERONET stations in South Africa, only one site has continuous AOD observations (from 1998 to 2008), that is, at Skukuza $\left(24^{\circ} \mathrm{S}\right.$, $31^{\circ} \mathrm{E}$; see Figure 1$)$. In the present work, quality-assured dataset (Level 2.0) of AERONET aerosol optical depth (AOD at $500 \mathrm{~nm}$ ) from this site is used for comparison with the AOD derived from the model simulations.

2.5.2. MISR Satellite Observation. Multiangle Imaging SpectroRadiometer (MISR) was launched by the National Aeronautics and Space Administration (NASA) on December 18, 1999 and has been in operation since February 2000. The device consists of nine push broom cameras arranged to view at nominal zenith angles relative to the surface reference ellipsoid of $0.0^{\circ}, \pm 26.1^{\circ}, \pm 45.6^{\circ}, 18 \pm 60.0^{\circ}$, and $\pm 70.5^{\circ}$ and measures upwelling short wave radiance in each camera at four spectral bands, centered at 446, 558, 672, and $866 \mathrm{~nm}$ [142]. With high spatial resolution and a better radiometrical and geometrical accuracy, the multiple angle-band observations of MISR allow the retrieval of a number of aerosol optical and microphysical properties over land (including a bright desert surfaces) and ocean [36-38, 100, 143-145]. Furthermore, MISR-AOD retrievals (level-3 data) have a higher grid resolution $\left(0.5^{\circ} \times 0.5^{\circ}\right)$ in comparison to the Moderate Resolution Imaging Spectroradiometer (MODIS) of Level-3 which has the resolution of $1^{\circ} \times 1^{\circ}$. In the present study from MISR-level-3-monthly-averaged datasets (version 31, which are available from 2000 onward), the AOD and SSA at $558 \mathrm{~nm}$ are utilized to evaluate the simulated results.

2.5.3. LIDAR Observation. A mobile LIDAR system was developed at the Council for Scientific and Industrial Research (CSIR), National Laser Centre (NLC), Pretoria $\left(25^{\circ} 5^{\circ} \mathrm{S} ; 28^{\circ} 2^{\circ} \mathrm{E}\right)$, South Africa [146, 147]. At present, the CSIR-NLC mobile LIDAR can provide aerosol backscatter measurements at $532 \mathrm{~nm}$ for the altitude region from ground to $40 \mathrm{~km}$ with a height resolution of $10 \mathrm{~m}$ [148-150]. For a better understanding of the atmospheric boundary layer evolution and aerosol concentrations, during October 2008 the LIDAR experiment has been performed at the University of Pretoria $\left(25.7^{\circ} \mathrm{S} ; 28.2^{\circ} \mathrm{E}\right)$. The experiment has been made continuous for 23 hour measurement, that is, from 16 October, $16 \mathrm{~h} 00$ to 17 October, $15 \mathrm{~h} 00$. To assess the model's performance in simulating the vertical distribution of aerosols, LIDAR retrieved extinction coefficient profiles from this experiment are compared with the corresponding modelsimulated results.

\section{Results and Discussion}

In the following subsections, we present the RegCM4-aerosol model's estimated aerosol optical field evaluation results, over South Africa. The magnitude and temporal variability of simulated columnar AOD comparison with AERONET and MISR observations at Skukuza $(24 \mathrm{~S}, 31 \mathrm{E})$ is given in Section 3.1. The latitudinal variations of simulated AODs 
and SSAs values within South Africa, in comparison with their corresponding column-integrated MISR retrievals, are provided in Section 3.2. Further, the simulated aerosol extinction coefficient profiles with respect to ground-based CSIRmobile LIDAR retrievals are presented in Section 3.3. The geographical location of the surface observation sites, that is, for AERONET and LIDAR, is shown in Figure 1. One of the important factors that propagate a bias in simulated aerosol concentration in model predicted aerosol optical fields is the model's insufficiency in simulating meteorological fields. In this context, even though the evaluation of model estimated meteorological parameters is beyond the scope and the aim of this study, to clarify some of the disparities between simulated and measured optical parameters, the bias in model estimated meteorological parameter, in comparison with specific meteorological sites, is presented in Appendix.

3.1. Comparisons with AERONET and MISR. The comparison of model-simulated monthly-averaged AOD (at $550 \mathrm{~nm}$ ) with the available data from AERONET (at $500 \mathrm{~nm}$ ) and MISR (at $558 \mathrm{~nm}$ ) observations at Skukuza $\left(24^{\circ} \mathrm{S}, 31^{\circ} \mathrm{E}\right)$, South Africa, is shown in Figure 2. Skukuza is situated in a region of the northeastern area of the Mpumalanga province (see Figure 1), which is relatively close to the major industrial areas of South Africa (i.e., Gauteng and western areas of Mpumalanga). This site is influenced by several aerosols, which are induced from various local activities, for instance, primary/secondary aerosols from frequently occurring local biomass burning activities (e.g., $[69,80]$ ), a variety of agricultural practices, and natural-resource based industrial activities, such as coal production (e.g., $[72,77]$ ). Besides, the conveyance of aerosols from the main industrial Highveld regions of South Africa and the slight contribution of long-range transported particles are the additional sources of aerosols for this site (e.g., $[85,151,152])$. In reproducing the magnitude of AERONET and MISR AOD values, the model relatively performs well. At least the magnitudes of simulated AODs are within the standard deviation of AERONET and $\pm 25 \%$ of MISR observations. The other important aspect in studying the climatic role of aerosols is the model's performance in capturing the temporal evolution of aerosol loading. In this regard, the model shows a good performance of capturing the seasonal and interannual variability of AOD (i.e., the temporal pattern of simulated AOD exhibits a temporal correlation coefficient of $\sim 0.6$ when compared with both observations).

Under cloud-free conditions, the AERONET AOD uncertainties for wavelengths $>400 \mathrm{~nm}$ are quite small $(< \pm 0.01$, [94]); therefore, taking AERONET measurements as a reference in our evaluation during some years one/two month advance/late predictions of maximal/minimal values of AOD by the model has been noted. Nevertheless, similar levels of temporal pattern inconsistencies, between AERONET and MISR measurements, are also seen. Such arbitrarily occurring temporal biases on simulated AODs are most likely related (at least partially associated) to three factors: (1) since the air quality around this site is strongly influenced by biomass burning events and different

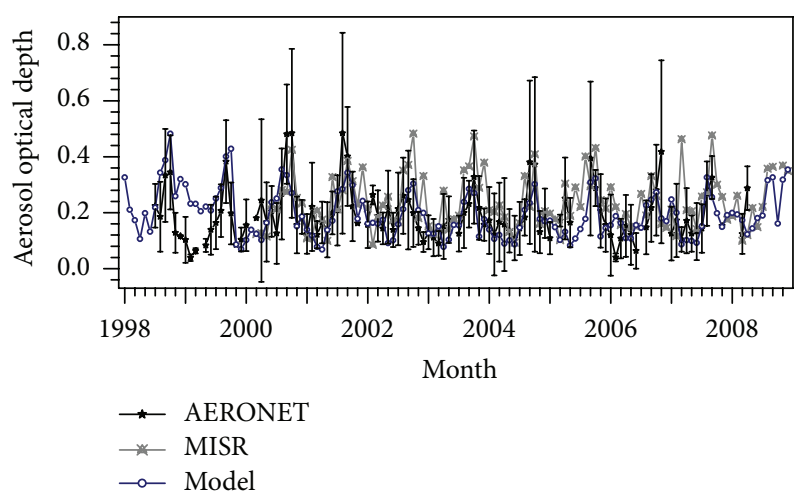

Figure 2: The comparison of RegCM4-aerosol model simulated monthly-averaged column-integrated aerosol extinction optical depth (at $550 \mathrm{~nm}$-blue solid line) with its corresponding observations derived from MISR (at $558 \mathrm{~nm}$-gray dotted line) and AERONET (at $500 \mathrm{~nm}$-black solid line denoting the values and standard deviation), at Skukuza, South Africa.

industrial activities, uncertainties associated with biomass burning/anthropogenic/sporadic urban emissions estimates by the emission inventories used in our simulations will impose such temporal biases (e.g., [80, 101]); (2) it is also likely that the bias in simulated meteorological fields could be a contributing factor in inducing temporal evolution biases on simulated aerosol concentrations, in turn in model predicted AOD patterns (e.g., $[30,34,57,153])$, and (3) biases that propagate from the interpolation scheme used to get model AOD at the AERONET site.

\subsection{Comparison of Simulated and MISR Satellite-Observed} $A O D$ and SSA Latitudinal Variations. In order to evaluate the model performance in capturing the spatial variability of column-integrated AODs and SSAs values, the simulated results are compared with MISR observations. The 9-year (i.e., from 2000 to 2008) simulated AOD and SSA values (at $550 \mathrm{~nm}$ ) are averaged over the longitudinal range, which encompasses only South Africa; subsequently their latitudinal variations (i.e., from the lower tip of Western Cape to the upper end of Limpopo, see Figure 1) in comparison with the corresponding MISR retrieved data (at $558 \mathrm{~nm}$ ) are presented in Figures 3(a) and 3(b), respectively. Over most of the latitudinal locations which correspond to Gauteng, Mpumalanga, North West, and Western Cape regions, the simulated columnar AOD values are within the standard deviation of MISR observations. However, over the latitudinal locations which comprise the Northern Cape, KwaZulu Natal, Free State, and most areas of the Eastern Cape regions, the model slightly overestimates the AOD values with respect to the MISR observations. In contrast, relative to MISR retrieval, the model underestimates the AOD signal in Limpopo province (i.e., within latitudinal range of $25.5^{\circ} \mathrm{S}$ to $22^{\circ} \mathrm{S}$ ). Within latitudinal ranges that extend from the southern tip of the Western Cape to central areas of Gauteng (except at $34.5^{\circ} \mathrm{S}$ ), the model's estimated SSA values are within the standard deviation of MISR observations. However, this comparison shows a slight positive bias that varies from +0.6 


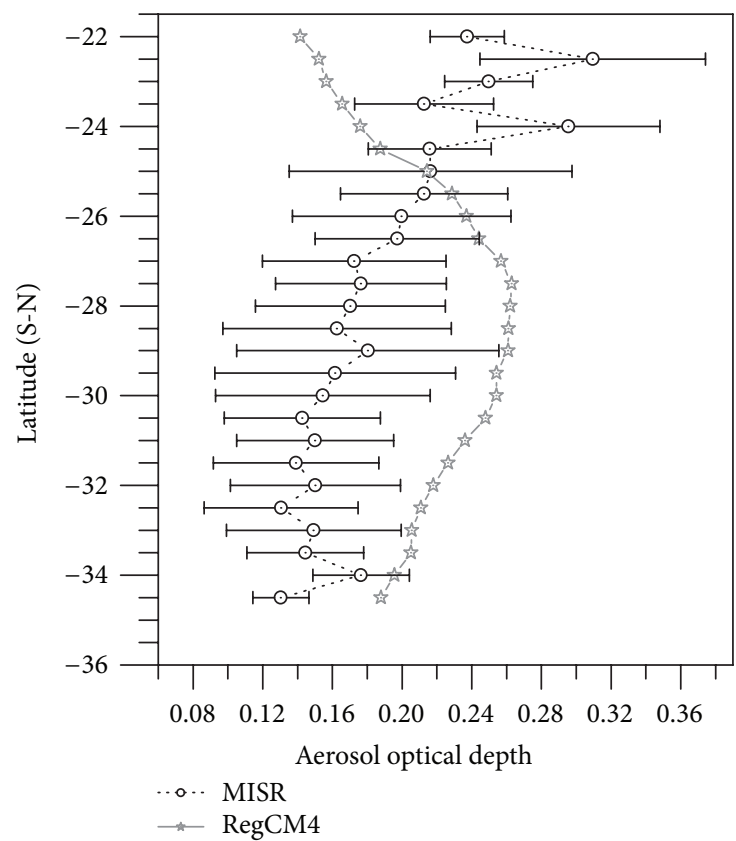

(a)

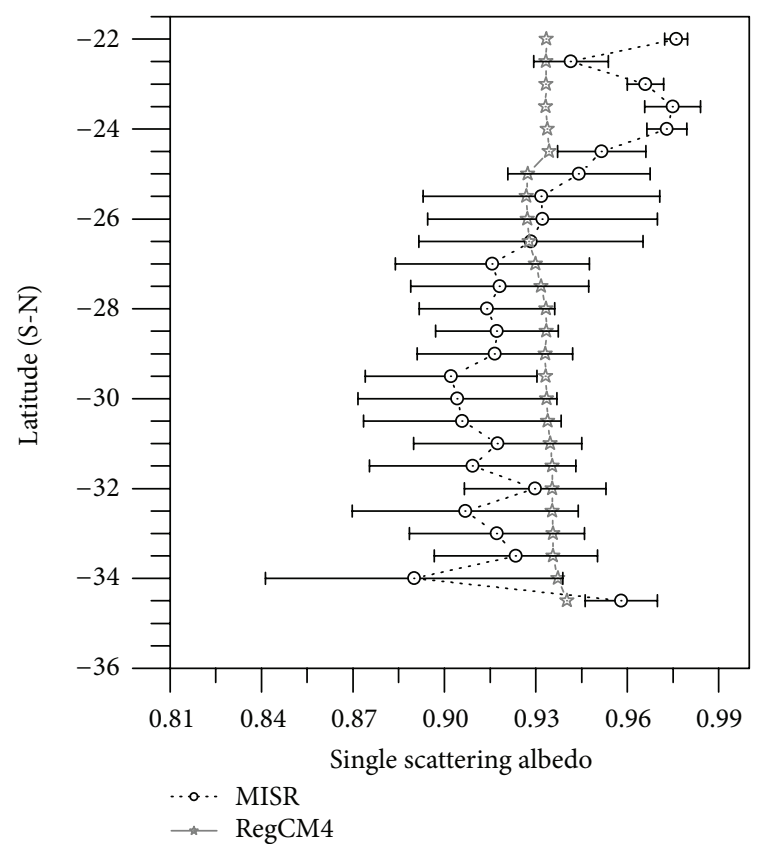

(b)

FIgURE 3: The latitudinal variation of the 9 years averaged column-integrated (a) AOD and (b) SSA values over South Africa, which are derived from MISR (at $558 \mathrm{~nm}$-black dot line denoting the values and its standard deviation) and the model (at $550 \mathrm{~nm}$ - gray solid line).

to $+4 \%$ relative to MISR mean values. For latitudinal locations which are above $25^{\circ} \mathrm{S}$ the model's predicted SSA values are lower than their corresponding MISR retrieved mean values.

The aerosol characteristics extracted from model simulations such as the distributions of atmospheric aerosol concentrations (in turn, their optical properties), the rate of production, and removal of particles are mostly controlled by meteorological parameters, which are highly variable both temporally and spatially (e.g., [2, 30, 31, 34, 153]). The model's performance in computing the actual precipitation values and patterns has a central role in determining the removal of aerosols from the atmosphere via wet deposition processes, as well as in regulating the soil moisture which in turn influences the dust production (e.g., $[30,31,63])$. As a result, the biases in the model's estimated precipitation values, in turn the aerosol concentrations, will significantly affect the robustness of simulated aerosol optical properties (e.g., [30, 57, 80, 154]). Even though it is not the intention of the current work to evaluate the simulated meteorological parameters, in order to decipher their contribution to the accuracy of model's estimated values of AOD and SSA, within a latitudinal range of $33.5^{\circ} \mathrm{S}$ to $27^{\circ} \mathrm{S}$, it is valuable to assess the bias in the model's estimated precipitation values. For this purpose, a single South African weather service (SAWS) metrological station's datasets (only one representative station per Province) are used as representative of these provinces and are compared with simulated results (see Appendix, Figures 4 and 5). The comparison period covers 108 months (from 2000 to 2008; please see Appendix). From the total compared months in Bloemfontein $\left(29.1^{\circ} \mathrm{S}, 26.3^{\circ} \mathrm{E}\right)$ which is in Free State and Upington $\left(28.4^{\circ} \mathrm{S}, 21.3^{\circ} \mathrm{E}\right)$ which is in Northern Cape, $\sim 80 \%$ of simulated precipitation values are in a negative bias (see Appendix, Figure 5).

The processes that control the dust emission through wind erosion are quite different to those involved in the anthropogenic/biomass burning emissions [29, 63]. The computation of naturally emitted dust production involves numerous criteria of land surface characterization. It also depends upon the model's capability of simulating different meteorological fields and land surface conditions. One of the surface parameters that determine the dust production is soil moisture (e.g., $[63,155])$ The model's predicted precipitation values exhibit a dry bias, which in turn will cause the surface to become dry and favorable for excessive dust particles emission depending on the wind intensity, [63, 156, 157]. Concurrently, the dry bias in simulated precipitation values will elongate the atmospheric residence time of the particles by reducing the wet removal rate (e.g., $[30,31,158])$. Soil dust particles do not readily dissolve in water ([159] and references therein); thus the negative bias in simulated precipitation will especially extend the atmospheric life-time of hydrophilic aerosols such as sulfate aerosols [30,80].

Within the simulation domain of the present work, the arid/semiarid regions of the Northern Cape, as well as Namibia and Botswana, are major sources of wind-induced desert dust particles over South Africa $([2,160]$ and references therein). Moreover, as presented in Tesfaye et al. [121] the largest contribution of sulfate aerosols to the total AOD is found in the Free State province of South Africa. In the visible part of the spectrum, excluding the slight absorption influence of larger dust particles [161], both dust and sulfate aerosols have a prevailing role of scattering (i.e., these aerosols 


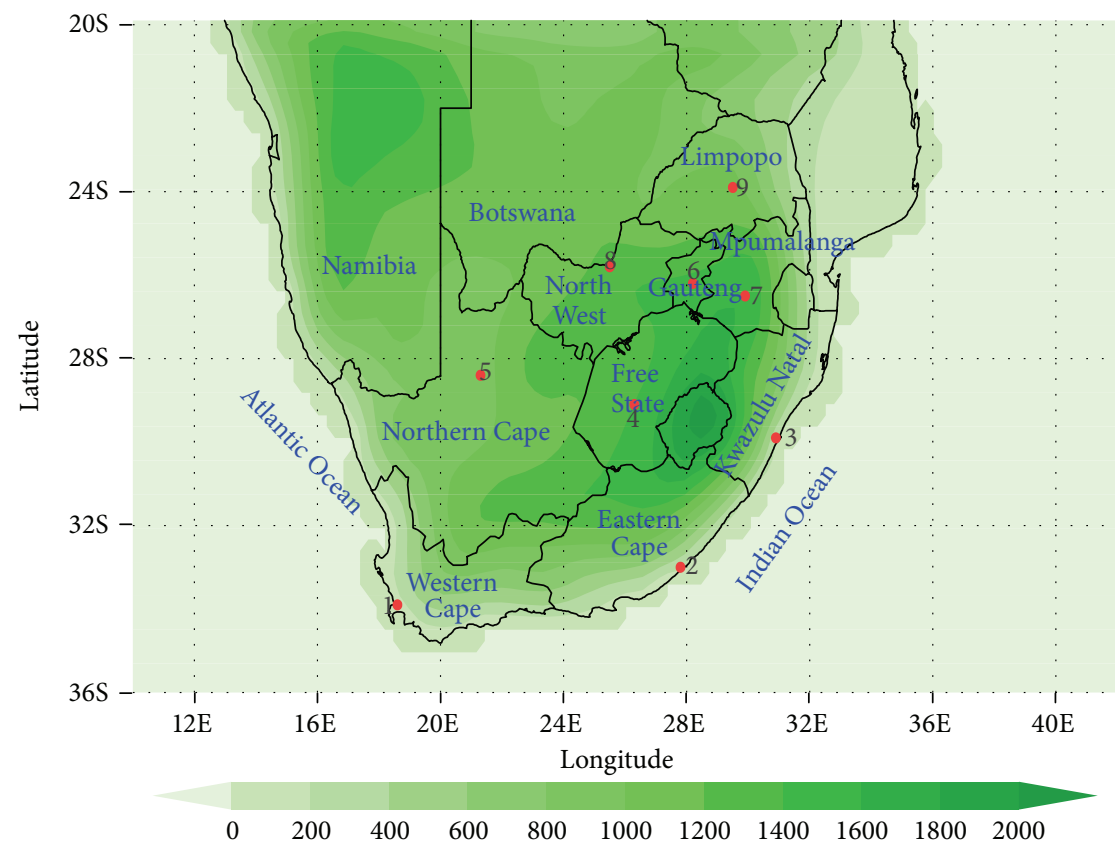

Figure 4: Model domain and topography (unit: $\mathrm{m}$ ). The selected SAWS station locations are numbered as (1) Cape Town (33.9 $\left.9^{\circ} \mathrm{S}, 18.6^{\circ} \mathrm{E}\right)$, (2) East London $\left(33.0^{\circ} \mathrm{S}, 27.8^{\circ} \mathrm{E}\right)$, (3) Durban South $\left(29.9^{\circ} \mathrm{S}, 30.9^{\circ} \mathrm{E}\right),(4)$ Bloemfontein $\left(29.1^{\circ} \mathrm{S}, 26.3^{\circ} \mathrm{E}\right),(5)$ Upington (28.4 $\left.4^{\circ} \mathrm{S}, 21.3^{\circ} \mathrm{E}\right),(6)$ Johannesburg (26.2 $\left.{ }^{\circ} \mathrm{S}, 28.2^{\circ} \mathrm{E}\right)$, (7) Ermelo (26.5 $\left.\mathrm{S}, 29.9^{\circ} \mathrm{E}\right)$, (8) Mafikeng (25.8 $\left.\mathrm{S}, 25.5^{\circ} \mathrm{E}\right)$, and (9) Polokwane $\left(23.9^{\circ} \mathrm{S}, 29.5^{\circ} \mathrm{E}\right)$.

have higher values of SSA) (e.g., [88, 90, 92]). Connecting all the aforementioned interrelated actualities, it is evident that within latitudinal range of $33.5^{\circ} \mathrm{S}$ to $27^{\circ} \mathrm{S}$ (i.e., which includes the Northern Cape and Free State provinces of South Africa as well as the nearby regions; see Figure 1), the model's estimated higher values of AOD and SSA (relative to MISR retrieval, Figure 3) may have been caused by the overestimated dust and sulfate aerosol atmospheric concentrations. This is also ensued due to the prevailing dry bias incidences around the primary source region of these aerosols (see Appendix, Figure 5).

Even though the arid/semiarid surfaces are the main source areas of dust particles, anthropogenic activities induced land surface degradations that are related to agricultural use, mining activities, and many other events result in an increment in wind-generated dust production (e.g., [162]). The areas of South Africa which are bounded within a latitudinal range of $25^{\circ} \mathrm{S}$ to $22^{\circ} \mathrm{S}$ (i.e., the Limpopo province) are highly populated with different mining and agricultural practices. Consequently, these activities will raise the dust emission in local and regional scales. However, the RegCM4 dust emission parameterizations are effective for cells which are dominated by desert and semidesert land cover only [63]. Therefore, primarily owing to the lack of cooperating anthropogenic activity-related dust production in Limpopo province (i.e., $25^{\circ} \mathrm{S}$ to $22^{\circ} \mathrm{S}$ ), the model underestimates the AOD, as well as SSA values with respect to MISR observations (Figure 3). Such bias, in turn, will affect the accuracy of the model's estimated direct and semi-direct radiative effects of total aerosols.

Due to the high dynamical nature of human activities, it is challenging to estimate anthropogenic events triggered by dust load. The above results notify the necessity of cooperating these particles for a better representation of bulk aerosol and its climatic roles in South Africa. Besides the above primary reason, the shortage of accounting the long-range transported particles in the model-especially from mining industries of Zambian to Limpopo areas $\left(25^{\circ} \mathrm{S}\right.$ to $22^{\circ} \mathrm{S}$ ) - will have a slight contribution to the observed essential differences in Figure 3 (e.g., [163]). As a final point, as indicated in Section 2, our simulation did not take into account marine aerosols. In the meanwhile, at Cape Town's $\left(33.9^{\circ} \mathrm{S}, 18.6^{\circ} \mathrm{E}\right)$ metrological site, largely positive biases in simulated precipitation values were noted (see Appendix, Figure 5), this will result in an overestimation of aerosol wet deposition (e.g., $[30,31])$. Therefore, most likely related to these two factors, the model's estimated SSA values around the Cape Point (i.e., $34.5^{\circ} \mathrm{S}$ ) are slightly underestimated with respect to MISR observations.

3.3. Comparisons with LIDAR. The aerosol extinction coefficient profiles that are retrieved from the LIDAR experiment $(532 \mathrm{~nm}$; see Section 2.5.3) on 16 October observation at 18:00 and 17 October at 00:00 and 06:00 were compared to their corresponding model results $(550 \mathrm{~nm})$ and provided in Figures 6(a)-6(c), respectively. In all comparisons, except at 18:00, both experimental and simulated profiles exhibit larger extinction coefficients below the altitude of $6 \mathrm{~km}$. Above $6 \mathrm{~km}$ (i.e., above $\sim 490 \mathrm{hPa}$ ), the simulated extinction profiles display a more rapid decline than the experimental observation. Especially on 16 October (at 18:00) and 17 October (at 06:00), considerable discrepancies between the model's and LIDAR's extinction profiles, above the height region of 


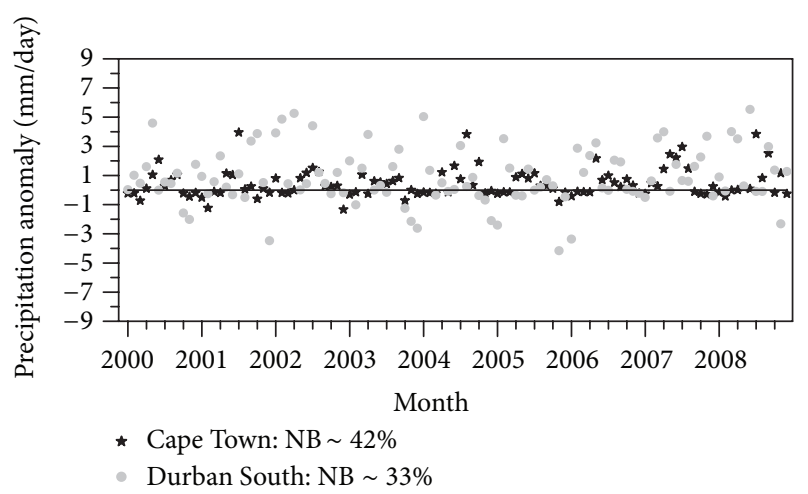

(a)

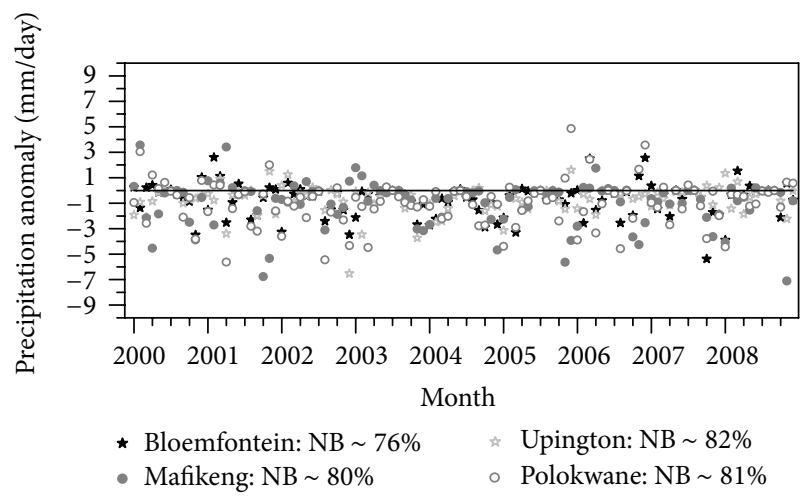

(b)

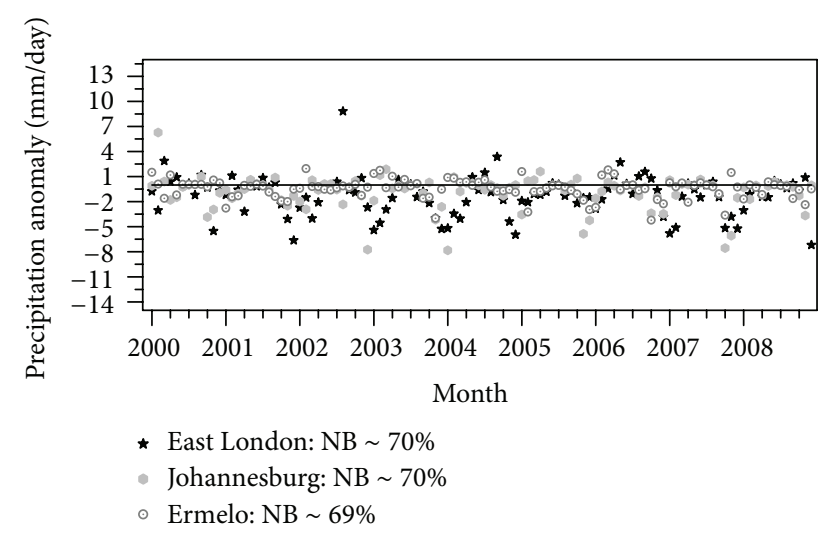

(c)

FIGURE 5: The bias in RegCM4 estimated total daily precipitation ( $\mathrm{mm} /$ day) in comparison with the specific metrological station's data. From the total compared months (108 months, i.e., 2000 to 2008) the percentage of the number of points that exhibit a negative bias (NB) is given in each plot.

$6 \mathrm{~km}$, have been noted. Using the same LIDAR datasets and air mass trajectory analysis, Tesfaye et al. [150] showed that particles above the height region of $6 \mathrm{~km}$ were particularly donated from long-range transportation processes. However, related with our future concern of investigating different types of aerosol impacts on South African climate-especially those which are originated in and around South Africa, we have configured the domain (see Figure 1), as well as the inflow/outflow boundary conditions, in order to account only for the natural and anthropogenic aerosol sources in and around South Africa. These configurations neglect the contribution of aerosols from external sources (which are outside of the domain) to the regional aerosol budget. This may partially attribute for the differences between experimental and simulated extinction profiles which are noted above the altitude profile of $6 \mathrm{~km}$.

In overall, to regulate the complex semidirect effect of aerosols-especially their role in cloud cover, studies have shown the importance of the relative position of the aerosol layer with respect to the cloud position (e.g., $[16,17]$ ). Nonetheless, there are several factors that will impose substantial inaccuracies on simulated profiles of aerosol optical properties such as, the model's deficiency in representing convective processes (e.g., $[57,65,68]$ ), the number of aerosol components which are cooperated in the model along with their mixing state hypothesis (e.g., $[5,124])$, and the various aspects which are mentioned in Section 1. Considering the presence of these all confining circumstances which will inflict discrepancies between simulated and LIDAR profiles, the model exhibits quite satisfactory performance in capturing the major aerosol extinction profiles. Although in our discussion several factors that will impose a bias on simulated aerosol optical signals are highlighted; at this scope of the study it is difficult to accurately assess the contribution of each factors in-depth and to point out which one is more responsible for enforcing these biases.

\section{Summary and Concluding Remarks}

Before we employ the Regional Climate Model-RegCM4 for the investigation of direct and semi-direct effects of aerosols over South Africa, in this study its performance to capture the observed aerosol optical properties has been evaluated and discussed. The evaluations were performed by comparing the simulated columnar Aerosol Optical Depth (AOD) and Single Scattering Albedo (SSA) against ground-based (AERONET) and satellite (Multiangle Imaging SpectroRadiometer: MISR) observations. Additionally, the simulated aerosol extinction profiles were compared with ground-based LIDAR retrieval. In our current contribution, the following conclusions can be drawn.

(i) At Skukuza $\left(24^{\circ} \mathrm{S}, 31^{\circ} \mathrm{E}\right)$, the values of simulated AOD were within the standard deviation of AERONET and $\pm 25 \%$ of MISR observations. Occasionally, the model-estimated maximum/minimum AOD values displayed a slight temporal shift with respect to AERONET observations. Nonetheless, such irregularly occurring temporal biases, as well as magnitude differences, are also noted among the MISR and AERONET platform estimates. In this frame, the model's simulated AOD climatology at Skukuza site is legitimately acceptable.

(ii) Considering the longitudinal range which includes only South Africa-the 9-year averaged values of simulated AOD and SSA latitudinal variations were also compared with the corresponding values retrieved 


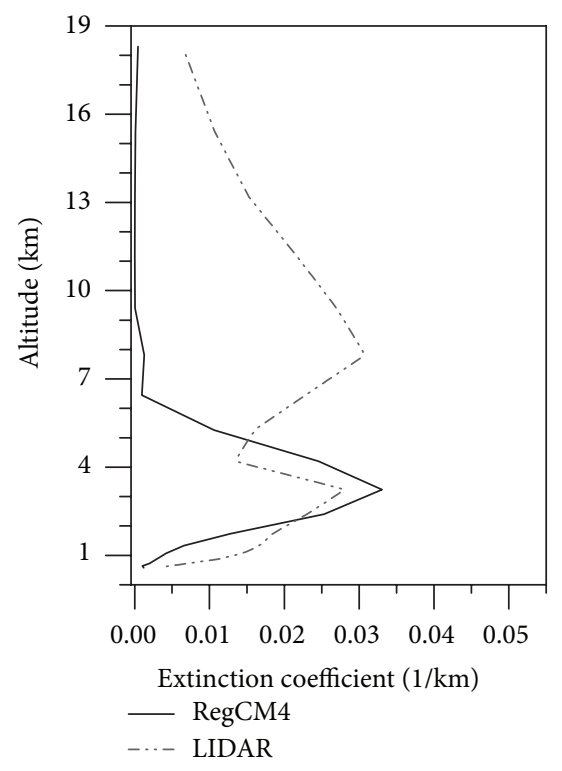

(a) 18:00

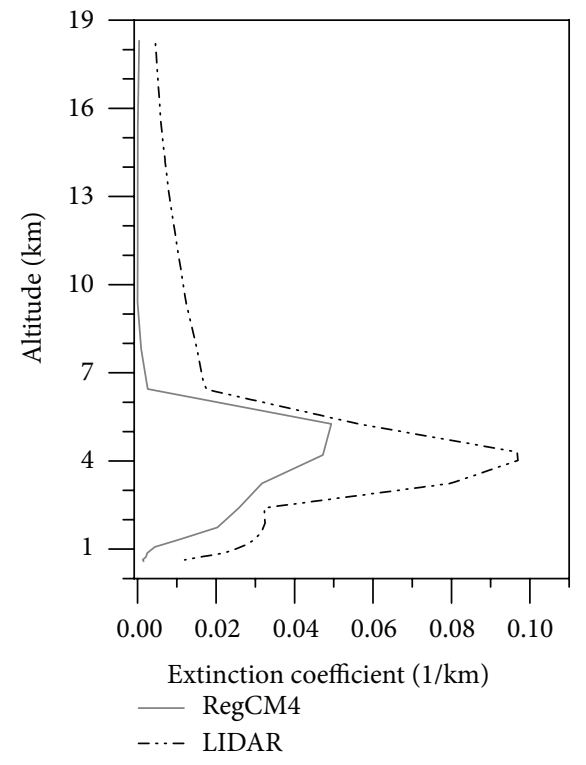

(b) 00:00

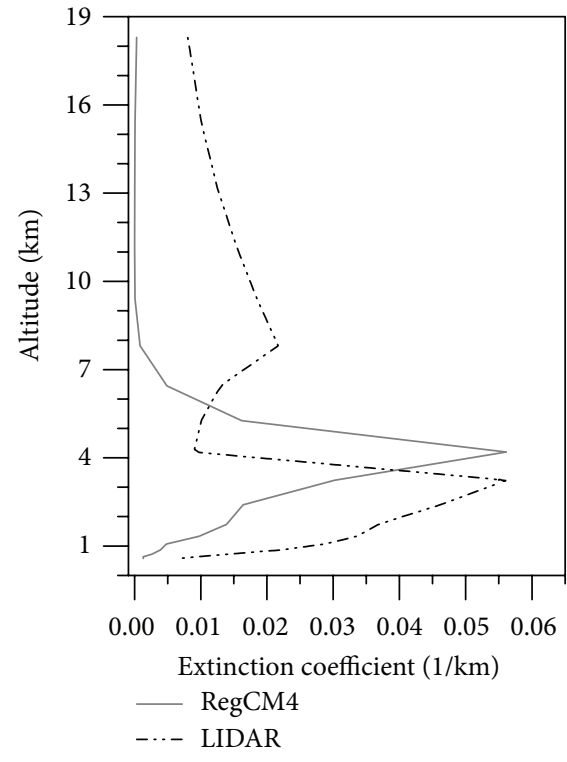

(c) $06: 00$

Figure 6: Aerosol extinction coefficient profiles, retrieved from LIDAR measurements at Pretoria (black dash-dot line) and its corresponding profiles provided by RegCM4 (gray line) (a) on 16 October at 18:00, (b) and (c) on 17 October at 00:00 and at 06:00, respectively.

from MISR observations. Within a latitudinal range of $26.5^{\circ} \mathrm{S}$ to $24.5^{\circ} \mathrm{S}$, the simulated columnar AOD values were within the standard deviation of MISR. However, within the regions of $33.5^{\circ} \mathrm{S}$ to $27^{\circ} \mathrm{S}$, the model tends to predict slightly higher values of AOD relative to MISR observation. This was predominantly caused by the negative (dry) bias in simulated precipitation that leads to the overestimation of dust and sulfate aerosol loads over these regions.

(iii) With respect to MISR, over the latitudinal range that corresponds to the Limpopo province (i.e., $25^{\circ} \mathrm{S}$ to $22^{\circ} \mathrm{S}$ ), the model underestimates both AOD and SSA signals. This was primarily due to the model's shortage in cooperating the anthropogenic activities prompted dust loads, such as dust from agricultural and mining practices. Therefore, in our region of interest (i.e., South Africa), this is considered as the main deficiency of RegCM4. Besides, in most of the latitudinal ranges, the simulated SSA values were within standard deviations of MISR observations.

(iv) Excluding the model's underestimated extinction coefficient profiles above $6 \mathrm{~km}$, RegCM4 performs very well in capturing the main aerosol extinction profiles, relative to LIDAR measurements. The aerosol extinction signals at higher altitude $(>6 \mathrm{~km})$ were donated by long-range transportation of particles from regions which were outside our simulation domain.

(v) Relative to observational data, the model fairly reproduced optical properties of aerosols. This affirmed that sulfate and carbonaceous aerosols from both anthropogenic and biomass burning activities and wind eroded desert dust particles were the main aerosol components in the South African atmosphere.

(vi) Overall, RegCM4 appeared to be a suitable tool for the examination of the direct and semi-direct effects of aerosols over the South African regional climate.

(vii) In the series of studies to follow, we will provide the distribution, direct and semi-direct effects of wind eroded desert dust particles, and the different species of aerosols which were induced from anthropogenic and biomass burning sectors, in South Africa [118121]. Thus, we would like to remark here that, in the present study, a bit of an extended general introduction, as well as a brief description about RegCM4, was addressed. Parts of these sections will be used as the basic framework for those of our future studies.

\section{Appendix}

The meteorological parameters such as precipitation, relative humidity, temperature, and wind speed play a major role in determining aerosol dynamics, as well as the changes in aerosol optical and physico-chemical properties (e.g., [2, 34, 153]). The model's deficiency in representing the actual precipitation values and patterns will impose a significant bias simulated aerosol production (via influencing surface wetness), as well as their atmospheric lifetime and concentration (via influencing wet aerosol deposition) [2, 30,31]. The biases in simulated aerosol concentrations will consequently affect the model's accuracy in computing the optical properties of aerosols. Therefore, comparing the simulated precipitation values, with respect to the South Africa Weather Service (SAWS) metrological station observations, the biases in 
model's predicted precipitation values are estimated. For this purpose, from each province of South Africa, a single weather service station is designated as a representative of these areas (Figure 4).

The bias in simulated total precipitation, while being compared to the datasets of the specific metrological sites, is shown in Figure 5. Generally, excluding the stations which are nearby the coastal areas of South Africa (i.e., Cape Town and Durban South stations, Figure 5(a)), the model predominantly exhibits a negative bias (Figures 5(b) and 5(c)); that is, out of total compared months in $75 \% \pm 5 \%$ of the points RegCM4 tends to underestimate the total daily precipitation values. The dry bias over the west (i.e., at Upington station, Figures 4 and 5(b)) and central (i.e., at Bloemfontein station, Figures 4 and 5(b)) parts of South Africa will promote the over emission of wind eroded dust particles and reduced wet deposition of hydrophilic aerosols. The precipitation bias in these comparisons has to be considered under caution; this is not a complete indicator of the overall performance of the model.

The model might actually be a demonstration of the region, but may not match exactly with the precise site observations. Further, the bias in metrological parameters can be induced by numerous complex factors such as radiation balance and energy flux inaccuracies induced through aerosol processes and surface properties (such as surface albedo), temperature advection, and cloud process representations $[30,57,68,164,165]$. However, determining the actual cause of these metrological parameter biases requires a further deep examination of the model's physics in representing the atmospheric dynamics, cloud, and surface processes as well as several other factors, which is beyond the scope of this study. Nevertheless, the expressive correlation between the biases in simulated AOD and precipitation values strengthens the remarkable importance of interactive coupling of aerosolclimate interactions.

\section{Acknowledgments}

The authors are grateful to Addis Ababa University, Department of Physics, for providing computational facilities. For the accessibility of RegCM model, the authors are thankful to the International Centre for Theoretical Physics (ICTP). The authors would like to acknowledge the AERONET, MISR, and SAWS for providing an easy access to the datasets used in this study. They are also indebted to Teresa Faleschini, Tamene Mekonnen, Fiona Tummon, and Addisu Gezahegn, for their valuable assistances. This work was supported by the African Laser Centre and NRF bi-lateral research grant (UID: 68688/65086), in addition to CSIR National Laser Centre.

\section{References}

[1] J. E. Penner, M. Andreae, H. Annegarn et al., "Aerosols, their direct and indirect effects," in Climate Change 2001: The Scientific Basis. Contribution of Working Group I to the Third Assessment Report of the Intergovernmental Panel on Climate Change, J. T. Houghton, Y. Ding, D. J. Griggs et al., Eds., pp. 289-348, Cambridge University Press, Cambridge, UK, 2001.
[2] M. Tesfaye, V. Sivakumar, J. Botai, and G. M. Tsidu, "Aerosol climatology over South Africa based on 10 years of multiangle imaging spectroradiometer (MISR) data," Journal of Geophysical Research D, vol. 116, no. 20, Article ID D20216, 2011.

[3] D. T. Shindell, H. Levy II, M. D. Schwarzkopf, L. W. Horowitz, J.-F. Lamarque, and G. Faluvegi, "Multi-model projections of climate change from short-lived emissions due to human activities," Journal of Geophysical Research, vol. 113, Article ID D11109, 2008.

[4] IPCC, "IPCC fourth assessment report (AR4)," in Climate Change 2007: The Physical Science Basis. Contribution of Working Group I to the Fourth Assessment Report of the Intergovernmental Panel on Climate Change, S. Solomon, D. Qin, M. Manning et al., Eds., p. 996, Cambridge University Press, Cambridge, UK, 2007.

[5] J. Haywood and O. Boucher, "Estimates of the direct and indirect radiative forcing due to tropospheric aerosols: a review," Reviews of Geophysics, vol. 38, no. 4, pp. 513-543, 2000.

[6] J. Hansen, M. Sato, R. Ruedy et al., "Efficacy of climate forcings," Journal of Geophysical Research, vol. 110, Article ID D18104, 2005.

[7] J. Hansen, M. Sato, and R. Ruedy, "Radiative forcing and climate response," Journal of Geophysical Research, vol. 102, no. 6, pp. 6831-6864, 1997.

[8] P. Forster, V. Ramaswamy, P. Artaxo et al., "Changes in atmospheric constituents and in radiative forcing," in Climate Change 2007: The Physical Science Basis. Contribution of Working Group I to the Fourth Assessment Report of the Intergovernmental Panel on Climate Change, S. Solomon, D. Qin, M. Manning et al., Eds., Cambridge University Press, Cambridge, UK, 2007.

[9] A. S. Ackerman, O. B. Toon, D. E. Stevens, A. J. Heymsfield, V. Ramanathan, and E. J. Welton, "Reduction of tropical cloudiness by soot," Science, vol. 288, no. 5468, pp. 1042-1047, 2000.

[10] R. L. Miller and I. Tegen, "Climate response to soil dust aerosols," Journal of Climate, vol. 11, no. 12, pp. 3247-3267, 1998.

[11] M. Z. Jacobson, "Control of fossil-fuel particulate black carbon and organic matter, possibly the most effective method of slowing global warming," Journal of Geophysical Research D, vol. 107, no. D19, p. 4410, 2005.

[12] I. Koren, Y. J. Kaufman, L. A. Remer, and J. V. Martins, "Measurement of the effect of Amazon smoke on inhibition of cloud formation," Science, vol. 303, no. 5662, pp. 1342-1345, 2004.

[13] J. Cook and E. J. Highwood, "Climate response to tropospheric absorbing aerosols in an intermediate general-circulation model," Quarterly Journal of the Royal Meteorological Society, vol. 130, no. 596, pp. 175-191, 2004.

[14] Y. Zhang, The radiative effect of aerosols from biomass burning on the transition from dry to wet season over the Amazon as tested by a regional climate model [Ph.D. thesis], Georgia Institute of Technology, Atlanta, Ga, USA, 2008.

[15] C. E. Chung, V. Ramanathan, and J. T. Kiehl, "Effects of the South Asian absorbing haze on the northeast monsoon and surface-air heat exchange," Journal of Climate, vol. 15, no. 17, pp. 2462-2476, 2002.

[16] B. T. Johnson, K. P. Shine, and P. M. Forster, "The semidirect aerosol effect: impact of absorbing aerosols on marine stratocumulus," Quarterly Journal of the Royal Meteorological Society, vol. 130, no. 599, pp. 1407-1422, 2004. 
[17] G. Feingold, H. Jiang, and J. Y. Harrington, "On smoke suppression of clouds in Amazonia," Geophysical Research Letters, vol. 32, no. 2, Article ID L02804, 2005.

[18] J. E. Penner, S. Y. Zhang, and C. C. Chuang, "Soot and smoke aerosol may not warm climate," Journal of Geophysical Research D, vol. 108, no. 21, pp. 1-9, 2003.

[19] D. Koch and A. D. Del Genio, "Black carbon semi-direct effects on cloud cover: review and synthesis," Atmospheric Chemistry and Physics, vol. 10, no. 16, pp. 7685-7696, 2010.

[20] R. J. Allen and S. C. Sherwood, "Aerosol-cloud semi-direct effect and land-sea temperature contrast in a GCM," Geophysical Research Letters, vol. 37, no. 7, Article ID L07702, 2010.

[21] S. Twomey, "The influence of pollution on the shortwave albedo of clouds," Journal of the Atmospheric Sciences, vol. 34, pp. 1149$1152,1977$.

[22] B. A. Albrecht, "Aerosols, cloud microphysics, and fractional cloudiness," Science, vol. 245, no. 4923, pp. 1227-1230, 1989.

[23] U. Lohmann and J. Feichter, "Global indirect aerosol effects: a review," Atmospheric Chemistry and Physics, vol. 5, no. 3, pp. 715-737, 2005.

[24] F. J. Dentener, G. R. Carmichael, Y. Zhang, J. Lelieveld, and P. J. Crutzen, "Role of mineral aerosol as a reactive surface in the global troposphere," Journal of Geophysical Research D, vol. 101, no. 17, pp. 22869-22889, 1996.

[25] R. R. Dickerson, S. Kondragunta, G. Stenchikov, K. L. Civerolo, B. G. Doddridge, and B. N. Holben, "The impact of aerosols on solar ultraviolet radiation and photochemical smog," Science, vol. 278, no. 5339, pp. 827-830, 1997.

[26] W. L. Chameides, H. Yu, S. C. Liu et al., "Case study of the effects of atmospheric aerosols and regional haze on agriculture: an opportunity to enhance crop yields in China through emission controls?" Proceedings of the National Academy of Sciences of the United States of America, vol. 96, no. 24, pp. 13626-13633, 1999.

[27] H. R. Anderson, "Differential epidemiology of ambient aerosols," Philosophical Transactions of the Royal Society A, vol. 358, no. 1775, pp. 2771-2785, 2000.

[28] G. Oberdorster, J. Finkelstein, J. Ferin et al., "Ultrafine particles as a potential environmental health hazard: studies with model particles," Chest, vol. 109, no. 3, 1996.

[29] F. Solmon, F. Giorgi, and C. Liousse, "Aerosol modelling for regional climate studies: application to anthropogenic particles and evaluation over a European/African domain," Tellus, Series $B$, vol. 58, no. 1, pp. 51-72, 2006.

[30] B. Croft, J. R. Pierce, R. V. Martin, C. Hoose, and U. Lohmann, "Uncertainty associated with convective wet removal of entrained aerosols in a global climate model," Atmospheric Chemistry and Physics, vol. 12, pp. 10725-10748, 2012.

[31] N. Oshima, Y. Kondo, N. Moteki et al., "Wet removal of black carbon in Asian outflow: Aerosol Radiative Forcing in East Asia (A-FORCE) aircraft campaign," Journal of Geophysical Research D, vol. 117, no. 3, Article ID D03204, 2012.

[32] D. T. Shindell, M. Chin, F. Dentener et al., "A multi-model assessment of pollution transport to the Arctic," Atmospheric Chemistry and Physics, vol. 8, no. 17, pp. 5353-5372, 2008.

[33] V. Ramanathan, P. J. Crutzen, J. Lelieveld et al., "Indian ocean experiment: an integrated analysis of the climate forcing and effects of the great Indo-Asian haze," Journal of Geophysical Research D, vol. 106, no. 22, pp. 28371-28398, 2001.

[34] D. Rind, M. Chin, G. Feingold et al., "Modeling the effects of aerosols on climate," in Atmospheric Aerosol Properties and Impacts on Climate, A Report by the U.S. Climate Change Science
Program and the Subcommittee on Global Change Research, M. Chin, R. A. Kahn, and S. E. Schwartz, Eds., pp. 64-97, National Aeronautics and Space Administration, 2009.

[35] E. Hirst, P. H. Kaye, R. S. Greenaway, P. Field, and D. W. Johnson, "Discrimination of micrometre-sized ice and super-cooled droplets in mixed-phase cloud," Atmospheric Environment, vol. 35, no. 1, pp. 33-47, 2001.

[36] D. J. Diner, B. H. Braswell, R. Davies et al., "The value of multiangle measurements for retrieving structurally and radiatively consistent properties of clouds, aerosols, and surfaces," Remote Sensing of Environment, vol. 97, no. 4, pp. 495-518, 2005.

[37] R. Kahn, P. Banerjee, and D. McDonald, "Sensitivity of multiangle imaging to natural mixtures of aerosols over ocean," Journal of Geophysical Research D, vol. 106, no. 16, pp. 18219-18238, 2001.

[38] R. A. Kahn, M. J. Garay, D. L. Nelson et al., "Satellite-derived aerosol optical depth over dark water from MISR and MODIS: comparisons with AERONET and implications for climatological studies," Journal of Geophysical Research D, vol. 112, no. 18, Article ID D18205, 2007.

[39] A. S. Goudie and N. J. Middleton, Desert Dust in the Global System, Springer, Berlin, Germany, 2006.

[40] M. Chin, P. Ginoux, S. Kinne et al., "Tropospheric aerosol optical thickness from the GOCART model and comparisons with satellite and sun photometer measurements," Journal of the Atmospheric Sciences, vol. 59, no. 3, pp. 461-483, 2002.

[41] S. H. Chung and J. H. Seinfeld, "Global distribution and climate forcing of carbonaceous aerosols," Journal of Geophysical Research D, vol. 107, no. 19, pp. 14-33, 2002.

[42] Y. Qian, F. Giorgi, Y. Huang, W. Chameides, and C. Luo, "Regional simulation of anthropogenic sulfur over East Asia and its sensitivity to model parameters," Tellus, Series B, vol. 53, no. 2, pp. 171-191, 2001.

[43] F. Giorgi, X. Bi, and Y. Qian, "Direct radiative forcing and regional climatic effects of anthropogenic aerosols over East Asia: a regional coupled climate-chemistry/aerosol model study," Journal of Geophysical Research D, vol. 107, no. 20, pp. 7-18, 2002.

[44] F. Giorgi, X. Bi, and Y. Qian, "Indirect vs. direct effects of anthropogenic sulfate on the climate of east Asia as simulated with a regional coupled climate-chemistry/aerosol model," Climatic Change, vol. 58, no. 3, pp. 345-376, 2003.

[45] A. M. L. Ekman and H. Rodhe, "Regional temperature response due to indirect sulfate aerosol forcing: impact of model resolution," Climate Dynamics, vol. 21, no. 1, pp. 1-10, 2003.

[46] T. Takemura, T. Nakajima, T. Nozawa, and K. Aoki, "Simulation of future aerosol distribution, radiative forcing, and long-range transport in East Asia," Journal of the Meteorological Society of Japan, vol. 79, no. 6, pp. 1139-1155, 2001.

[47] I. Tegen, M. Werner, S. P. Harrison, and K. E. Kohfeld, "Relative importance of climate and land use in determining present and future global soil dust emission," Geophysical Research Letters, vol. 31, no. 5, pp. L05105-4, 2004.

[48] A. Baklanov, B. Fay, G. Weather et al., "Overview of existing integrated (off-line and on-line) mesoscale systems in Europe," report of Working Group 2, 2007, http://www.cost728.org/.

[49] A. Baklanov, A. Mahura, and R. Sokhi, Integrated Systems of Meso-Meteorological and Chemical Transport Models, Springer, New York, NY, USA, 2011.

[50] F. Giorgi, E. Coppola, F. Solmon et al., "RegCM4: model description and preliminary tests over multiple CORDEX domains," Climate Research, vol. 52, pp. 7-29, 2012. 
[51] M. Kanakidou, J. H. Seinfeld, S. N. Pandis et al., "Organic aerosol and global climate modelling: a review," Atmospheric Chemistry and Physics, vol. 5, no. 4, pp. 1053-1123, 2005.

[52] X. Liu, J. E. Penner, B. Das et al., "Uncertainties in global aerosol simulations: assessment using three meteorological data sets," Journal of Geophysical Research D, vol. 112, no. 11, Article ID D11212, 2007.

[53] E. Vignati, M. Karl, M. Krol, J. Wilson, P. Stier, and F. Cavalli, "Sources of uncertainties in modelling black carbon at the global scale," Atmospheric Chemistry and Physics, vol. 10, no. 6, pp. 2595-2611, 2010.

[54] L. Lee, K. J. Pringle, C. L. Reddington et al., "The magnitude and causes of uncertainty in global model simulations of cloud condensation nuclei," Atmospheric Chemistry and Physics, vol. 13, pp. 6295-6378, 2013.

[55] G. Myhre, F. Stordal, T. F. Berglen, J. K. Sundet, and I. S. A. Isaksen, "Uncertainties in the radiative forcing due to sulphate aerosols," Journal of the Atmospheric Sciences, vol. 61, no. 5, pp. 485-498, 2004.

[56] M. Schulz, C. Textor, S. Kinne et al., "Radiative forcing by aerosols as derived from the AeroCom present-day and preindustrial simulations," Atmospheric Chemistry and Physics, vol. 6, no. 12, pp. 5225-5246, 2006.

[57] H. Tost, M. G. Lawrence, C. Brühl, and P. Jöckel, "Uncertainties in atmospheric chemistry modelling due to convection parameterisations and subsequent scavenging," Atmospheric Chemistry and Physics, vol. 10, no. 4, pp. 1931-1951, 2010.

[58] P. Stier, N. A. J. Schutgens, N. Bellouin et al., "Host model uncertainties in aerosol radiative forcing estimates: results from the AeroCom prescribed inter-comparison study," Atmospheric Chemistry and Physics, vol. 13, pp. 3245-3270, 2013.

[59] F. Giorgi and M. R. Marinucci, "An investigation of the sensitivity of simulated precipitation to model resolution and its implications for climate studies," Monthly Weather Review, vol. 124, no. 1, pp. 148-166, 1996.

[60] F. Giorgi and C. Shields, "Tests of precipitation parameterizations available in latest version of NCAR regional climate model (RegCM) over continental United States," Journal of Geophysical Research D, vol. 104, no. 6, pp. 6353-6375, 1999.

[61] F. Giorgi and R. O. Anyah, "Evolution of regional climate modeling: the road towards RegCM4," Climate Research, vol. 52, pp. 3-6, 2012.

[62] M.Z. Jacobson, Developing, coupling, and applying a gas, aerosol, transport, and radiation model to study urban and regional air pollution [Ph.D. thesis], Department of Atmospheric Sciences, University of California, Los Angeles, Calif, USA, 1994.

[63] A. S. Zakey, F. Solmon, and F. Giorgi, "Implementation and testing of a desert dust module in a regional climate model," Atmospheric Chemistry and Physics, vol. 6, no. 12, pp. 46874704, 2006

[64] A. S. Zakey, F. Giorgi, and X. Bi, "Modeling of sea salt in a regional climate model: fluxes and radiative forcing," Journal of Geophysical Research D, vol. 113, no. 14, Article ID D14221, 2008.

[65] P. Zanis, C. Douvis, I. Kapsomenakis, I. Kioutsioukis, D. Melas, and J. S. Pal, "A sensitivity study of the Regional Climate Model (RegCM3) to the convective scheme with emphasis in central eastern and southeastern Europe," Theoretical and Applied Climatology, vol. 97, no. 3-4, pp. 327-337, 2009.

[66] Y. Zhang, X.-Y. Wen, and C. J. Jang, "Simulating chemistryaerosol-cloud-radiation-climate feedbacks over the continental U.S. using the online-coupled Weather Research Forecasting
Model with chemistry (WRF/Chem)," Atmospheric Environment, vol. 44, no. 29, pp. 3568-3582, 2010.

[67] F. Solmon, M. Mallet, N. Elguindi, F. Giorgi, A. Zakey, and A. Konaré, "Dust aerosol impact on regional precipitation over western Africa, mechanisms and sensitivity to absorption properties," Geophysical Research Letters, vol. 35, no. 24, Article ID L24705, 2008.

[68] F. Solmon, N. Elguindi, and M. Mallet, "Radiative and climatic effects of dust over West Africa, as simulated by a regional climate model," Climate Research, vol. 52, pp. 97-113, 2012.

[69] F. Tummon, F. Solmon, C. Liousse, and M. Tadross, "Simulation of the direct and semidirect aerosol effects on the southern Africa regional climate during the biomass burning season," Journal of Geophysical Research D, vol. 115, no. 19, Article ID D19206, 2010.

[70] A. Konare, A. S. Zakey, F. Solmon et al., "A regional climate modeling study of the effect of desert dust on the West African monsoon," Journal of Geophysical Research D, vol. 113, no. 12, Article ID D12206, 2008.

[71] F. Malavelle, V. Pont, M. Mallet et al., "Simulation of aerosol radiative effects over West Africa during DABEX and AMMA SOP-0," Journal of Geophysical Research D, vol. 116, no. 8, Article ID D08205, 2011.

[72] Eskom, "Effects of atmospheric pollution on the Mpumalanga Highveld," Power Technology No. 70, Eskom Technology Group, Cleveland, South Africa, 1996.

[73] R. Spalding-Fecher and D. K. Matibe, "Electricity and externalities in South Africa," Energy Policy, vol. 31, no. 8, pp. 721-734, 2003.

[74] K. E. Ross, S. J. Piketh, R. T. Bruintjes, R. P. Burger, R. J. Swap, and H. J. Annegarn, "Spatial and aerosol variations in CCN distribution and the aerosol-CCN relationship over southern Africa," Journal of Geophysical Research D, vol. 108, no. 13, pp. $1-18,2003$.

[75] A. J. Mills, A. V. Milewski, C. Sirami et al., "Aerosol capture by small trees in savannas marginal to treeless grassland in South Africa," Geoderma, vol. 189-190, pp. 124-132, 2012.

[76] H. Winkler, P. Formenti, D. J. Esterhuyse et al., "Evidence for large-scale transport of biomass burning aerosols from sunphotometry at a remote South African site," Atmospheric Environment, vol. 42, no. 22, pp. 5569-5578, 2008.

[77] A. J. Queface, S. J. Piketh, T. F. Eck, S.-C. Tsay, and A. F. Mavume, "Climatology of aerosol optical properties in Southern Africa," Atmospheric Environment, vol. 45, no. 17, pp. 2910-2921, 2011.

[78] B. I. Magi, "Chemical apportionment of southern African aerosol mass and optical depth," Atmospheric Chemistry and Physics, vol. 9, no. 19, pp. 7643-7655, 2009.

[79] M. Tesfaye, V. Sivakumar, J. Botai, and G. Mengistu, "Latitudinal variations of aerosol optical parameters over South Africa based on MISR satellite data," in Proceedings of the 26th Annual Conference of South African Society for Atmosphere Science, pp. 105-106, September 2010.

[80] F. Tummon, Direct and semi-direct aerosol effects on the southern African regional climate during the austral winter season [Ph.D. thesis], University of Cape Town, Cape Town, South Africa, 2011.

[81] B. I. Magi, P. Ginoux, Y. Ming, and V. Ramaswamy, "Evaluation of tropical and extratropical Southern Hemisphere African aerosol properties simulated by a climate model," Journal of Geophysical Research D, vol. 114, no. 14, Article ID D14204, 2009.

[82] T. F. Eck, B. N. Holben, D. E. Ward et al., "Variability of biomass burning aerosol optical characteristics in southern 
Africa during the SAFARI 2000 dry season campaign and a comparison of single scattering albedo estimates from radiometric measurements," Journal of Geophysical Research D, vol. 108, no. 13, pp. 1-21, 2003.

[83] R. J. Swap, H. J. Annegarn, J. T. Suttles et al., “The Southern African Regional Science Initiative (SAFARI 2000): overview of the dry season field campaign," South African Journal of Science, vol. 98, no. 3-4, pp. 125-130, 2002.

[84] R. J. Swap, H. J. Annegarn, J. T. Suttles et al., "Africa burning: a thematic analysis of the Southern African Regional Science Initiative (SAFARI 2000)," Journal of Geophysical Research D, vol. 108, no. 13, pp. 1-15, 2003.

[85] S. J. Piketh, H. J. Annegarn, and P. D. Tyson, "Lower tropospheric aerosol loadings over South Africa: the relative contribution of aeolian dust, industrial emissions, and biomass burning," Journal of Geophysical Research D, vol. 104, no. 1, pp. 1597-1607, 1999.

[86] J. M. Prospero, P. Ginoux, O. Torres, S. E. Nicholson, and T. E. Gill, "Environmental characterization of global sources of atmospheric soil dust identified with the Nimbus 7 Total Ozone Mapping Spectrometer (TOMS) absorbing aerosol product," Reviews of Geophysics, vol. 40, no. 1, pp. -1-31, 2002.

[87] O. Dubovik and M. D. King, "A flexible inversion algorithm for retrieval of aerosol optical properties from Sun and sky radiance measurements," Journal of Geophysical Research D, vol. 105, no. 16, pp. 20673-20696, 2000.

[88] C. Levoni, M. Cervino, R. Guzzi, and F. Torricella, "Atmospheric aerosol optical properties: a database of radiative characteristics for different components and classes," Applied Optics, vol. 36, no. 30, pp. 8031-8041, 1997.

[89] M. I. Mishchenko and L. D. Travis, Light Scattering by NonSpherical Particles, Academic Press, San-Diego, Calif, USA, 2000.

[90] M. Hess, P. Koepke, and I. Schult, "Optical properties of aerosols and clouds: the software package OPAC," Bulletin of the American Meteorological Society, vol. 79, no. 5, pp. 831-844, 1998.

[91] E. Andrews, P. J. Sheridan, M. Fiebig et al., "Comparison of methods for deriving aerosol asymmetry parameter," Journal of Geophysical Research, vol. 111, no. D5, Article ID D05S04, 2006.

[92] T. Takemura, T. Nakajima, O. Dubovik, B. N. Holben, and S. Kinne, "Single-scattering albedo and radiative forcing of various aerosol species with a global three-dimensional model," Journal of Climate, vol. 15, no. 4, pp. 333-352, 2002.

[93] J. H. Seinfeld and S. N. Pandis, Atmospheric Chemistry and Physics: From Air Pollution to Climate, Wiley, New York, NY, USA, 2006.

[94] O. Dubovik, A. Smirnov, B. N. Holben et al., "Accuracy assessments of aerosol optical properties retrieved from Aerosol Robotic Network (AERONET) Sun and sky radiance measurements," Journal of Geophysical Research D, vol. 105, no. 8, pp. 9791-9806, 2000.

[95] H. Yu, Y. J. Kaufman, M. Chin et al., "A review of measurementbased assessments of the aerosol direct radiative effect and forcing," Atmospheric Chemistry and Physics, vol. 6, no. 3, pp. 613-666, 2006.

[96] Y. J. Kaufman, D. Tanré, L. A. Remer, E. F. Vermote, A. Chu, and B. N. Holben, "Operational remote sensing of tropospheric aerosol over land from EOS moderate resolution imaging spectroradiometer," Journal of Geophysical Research D, vol. 102, no. 14, pp. 17051-17067, 1997.
[97] P. Chylek, B. Henderson, and M. Mishchenko, "Aerosol radiative forcing and the accuracy of satellite aerosol optical depth retrieval," Journal of Geophysical Research D, vol. 108, no. 24, pp. 4-8, 2003.

[98] D. Tanré, Y. J. Kaufman, M. Herman, and S. Mattoo, "Remote sensing of aerosol properties over oceans using the MODIS/EOS spectral radiances," Journal of Geophysical Research D, vol. 102, no. 14, pp. 16971-16988, 1997.

[99] R. A. Kahn, B. J. Gaitley, J. V. Martonchik, D. J. Diner, K. A. Crean, and B. Holben, "Multiangle Imaging Spectroradiometer (MISR) global aerosol optical depth validation based on 2 years of coincident Aerosol Robotic Network (AERONET) observations," Journal of Geophysical Research D, vol. 110, no. 10, pp. 1-16, 2005.

[100] O. V. Kalashnikova, R. Kahn, I. N. Sokolik, and W.-H. Li, "Ability of multiangle remote sensing observations to identify and distinguish mineral dust types: optical models and retrievals of optically thick plumes," Journal of Geophysical Research D, vol. 110, no. 18, Article ID D18S14, pp. 1-16, 2005.

[101] A. De Meij, M. Krol, F. Dentener, E. Vignati, C. Cuvelier, and P. Thunis, "The sensitivity of aerosol in Europe to two different emission inventories and temporal distribution of emissions," Atmospheric Chemistry and Physics, vol. 6, no. 12, pp. 42874309, 2006.

[102] N. Mahowald, K. Kohfeld, M. Hansson et al., "Dust sources and deposition during the last glacial maximum and current climate: a comparison of model results with paleodata from ice cores and marine sediments," Journal of Geophysical Research D, vol. 104, no. 13, pp. 15895-15916, 1999.

[103] Y. J. Kaufman, D. Tanré, and O. Boucher, "A satellite view of aerosols in the climate system," Nature, vol. 419, no. 6903, pp. 215-223, 2002.

[104] D. J. Diner, T. P. Ackerman, T. L. Anderson et al., "Paragon: an integrated approach for characterizing aerosol climate impacts and environmental interactions," Bulletin of the American Meteorological Society, vol. 85, pp. 14911-11501, 2004.

[105] J. E. Penner, S. Y. Zhang, M. Chin et al., "A comparison of modeland satellite-derived aerosol optical depth and reflectivity," Journal of the Atmospheric Sciences, vol. 59, no. 3, pp. 441-460, 2002.

[106] R. E. Dickinson, R. M. Errico, F. Giorgi, and G. T. Bates, "A regional climate model for the western United States," Climatic Change, vol. 15, no. 3, pp. 383-422, 1989.

[107] J. T. Kiehl, J. J. Hack, G. B. Bonan et al., "Description of the ncar community climate model (ccm3)," Tech. Rep. NCAR/TN420+STR, National Center for Atmospheric Research, 1996.

[108] X. Zeng, M. Zhao, and R. E. Dickinson, "Intercomparison of bulk aerodynamic algorithms for the computation of sea surface fluxes using TOGA COARE and TAO data," Journal of Climate, vol. 11, no. 10, pp. 2628-2644, 1998.

[109] R. E. Dickinson, A. Henderson-Sellers, and P. J. Kennedy, "Biosphere-atmosphere transfer scheme (bats) version le as coupled to the ncar community climate model," Tech. Rep. NCAR/TN-387+STR, National Center for Atmospheric Research, 1993.

[110] F. Giorgi, R. Francisco, and J. Pal, "Effects of a subgrid-scale topography and land use scheme on the simulation of surface climate and hydrology. Part 1: effects of temperature and water vapor disaggregation," Journal of Hydrometeorology, vol. 4, pp. 317-333, 2003.

[111] A. A. M. Holtslag, E. I. F. De Bruijn, and H.-L. Pan, "A high resolution air mass transformation model for short-range 
weather forecasting," Monthly Weather Review, vol. 118, no. 8, pp. 1561-1575, 1990.

[112] G. A. Grell, "Prognostic evaluation of assumptions used by cumulus parameterizations," Monthly Weather Review, vol. 121, no. 3, pp. 764-787, 1993.

[113] J. M. Fritsch and C. F. Chappell, "Numerical prediction of convectively driven mesoscale pressure systems. Part I: convective parameterization," Journal of the Atmospheric Sciences, vol. 37, no. 8, pp. 1722-1733, 1980.

[114] J. S. Pal, E. E. Small, and E. A. B. Eltahir, "Simulation of regionalscale water and energy budgets: representation of subgrid cloud and precipitation processes within RegCM," Journal of Geophysical Research D, vol. 105, no. 24, pp. 29579-29594, 2000.

[115] Y. Huang, W. L. Chameides, Q. Tan, and R. E. Dickinson, "Characteristics of anthropogenic sulfate and carbonaceous aerosols over East Asia: regional modeling and observation," Advances in Atmospheric Sciences, vol. 25, no. 6, pp. 946-959, 2008.

[116] D. F. Zhang, A. S. Zakey, X. J. Gao, F. Giorgi, and F. Solmon, "Simulation of dust aerosol and its regional feedbacks over East Asia using a regional climate model," Atmospheric Chemistry and Physics, vol. 9, no. 4, pp. 1095-1110, 2009.

[117] M. Santese, M. R. Perrone, A. S. Zakey, F. De Tomasi, and F. Giorgi, "Modeling of Saharan dust outbreaks over the mediterranean by RegCM3: case studies," Atmospheric Chemistry and Physics, vol. 10, no. 1, pp. 133-156, 2010.

[118] M. Tesfaye et al., "Mineral dust aerosol distributions, its direct and semi-direct effects over South Africa based on regional climate model simulation," submitted to a peer-reviewed journal and currently, 2013, ftp://ftp.csir.co.za/NLC/EE/.

[119] M. Tesfaye et al., "Simulation of anthropogenic aerosols mass distributions and their direct and semi-direct effects over South Africa using RegCM4," submitted to a peer-reviewed journal and currently, 2013, ftp://ftp.csir.co.za/NLC/EE/.

[120] M. Tesfaye et al., "Simulation of biomass burning aerosols mass distributions and their direct and semi-direct effects over South Africa using a regional climate model," submitted to a peer-reviewed journal and currently, 2013, $\mathrm{ftp}: / / \mathrm{ftp} . c s i r . c o . z a / \mathrm{NLC} / \mathrm{EE} /$.

[121] M. Tesfaye et al., "Simulation of bulk aerosol direct andsemi-direct effects in South Africa using RegCM4," submitted to a peer-reviewed journal and currently, 2013, $\mathrm{ftp}: / / \mathrm{ftp} . c s i r . c o . z a / N L C / E E /$.

[122] C. Liousse, F. Dulac, H. Cachier, and D. Tanré, "Remote sensing of carbonaceous aerosol production by African savanna biomass burning," Journal of Geophysical Research D, vol. 102, no. 5, pp. 5895-5911, 1997.

[123] S. Fuzzi, M. O. Andreae, B. J. Huebert et al., "Critical assessment of the current state of scientific knowledge, terminology, and research needs concerning the role of organic aerosols in the atmosphere, climate, and global change," Atmospheric Chemistry and Physics, vol. 6, no. 7, pp. 2017-2038, 2006.

[124] G. Lesins, P. Chylek, and U. Lohmann, "A study of internal and external mixing scenarios and its effect on aerosol optical properties and direct radiative forcing," Journal of Geophysical Research D, vol. 107, no. 9-10, pp. 5-1, 2002.

[125] S. E. Bauer and D. Koch, "Impact of heterogeneous sulfate formation at mineral dust surfaces on aerosol loads and radiative forcing in the Goddard Institute for Space Studies general circulation model," Journal of Geophysical Research D, vol. 110, no. 17, Article ID D17202, pp. 91-105, 2005.
[126] M. Z. Jacobson, "Strong radiative heating due to the mixing state of black carbon in atmospheric aerosols," Nature, vol. 409, no. 6821, pp. 695-697, 2001.

[127] R. C. Moffet and K. A. Prather, "In-situ measurements of the mixing state and optical properties of soot with implications for radiative forcing estimates," Proceedings of the National Academy of Sciences of the United States of America, vol. 106, no. 29, pp. 11872-11877, 2009.

[128] G. McFiggans, P. Artaxo, U. Baltensperger et al., "The effect of physical and chemical aerosol properties on warm cloud droplet activation," Atmospheric Chemistry and Physics, vol. 6, no. 9, pp. 2593-2649, 2006.

[129] M. Tesfaye, M. Tsidu, V. Sivakumar, and J. Botai, "Effective single scattering albedo estimation using regional climate model," in Proceedings of the 27th Annual Conference of the South African Society for Atmospheric Sciences: The Interdependent Atmosphere, Land and Ocean, Hartbeespoort, pp. 53-54, September 2011.

[130] M. Tesfaye, Retrival of atmospheric aerosol optical and microphysical parameters from ground base passive remote sensing measurement over Addis Ababa [M.S. thesis], Addis Ababa University, Addis Ababa, Ethiopia, 2009.

[131] J.-F. Lamarque, T. C. Bond, V. Eyring et al., "Historical (18502000) gridded anthropogenic and biomass burning emissions of reactive gases and aerosols: methodology and application," Atmospheric Chemistry and Physics, vol. 10, no. 15, pp. 70177039, 2010.

[132] G. R. van der Werf, J. T. Randerson, L. Giglio et al., "Global fire emissions and the contribution of deforestation, savanna, forest, agricultural, and peat fires (1997-2009)," Atmospheric Chemistry and Physics, vol. 10, no. 23, pp. 11707-11735, 2010.

[133] L. Giglio, J. T. Randerson, G. R. Van Der Werf et al., "Assessing variability and long-term trends in burned area by merging multiple satellite fire products," Biogeosciences, vol. 7, no. 3, pp. 1171-1186, 2010.

[134] G. R. van der Werf, J. T. Randerson, L. Giglio, G. J. Collatz, P. S. Kasibhatla, and A. F. Arellano Jr., "Interannual variability in global biomass burning emissions from 1997 to 2004," Atmospheric Chemistry and Physics, vol. 6, no. 11, pp. 3423-3441, 2006.

[135] A. Seth and F. Giorgi, "The effects of domain choice on summer precipitation simulation and sensitivity in a regional climate model," Journal of Climate, vol. 11, no. 10, pp. 2698-2712, 1998.

[136] X. Wang, Z. Zhong, Y. Hu, and H. Yuan, "Effect of lateral boundary scheme on the simulation of tropical cyclone track in regional climate model RegCM3," Asia-Pacific Journal of Atmospheric Sciences, vol. 46, no. 2, pp. 221-230, 2010.

[137] A. Simmons, S. Uppala, D. Dee, and S. Kobayashi, "ERAInterim: new ECMWF reanalysis products from 1989 onwards," ECMWF Newsletter, vol. 110, pp. 25-35, 2007.

[138] D. P. Dee, S. M. Uppala, A. J. Simmons et al., “The ERA-Interim reanalysis: configuration and performance of the data assimilation system," Quarterly Journal of the Royal Meteorological Society, vol. 137, no. 656, pp. 553-597, 2011.

[139] R. W. Reynolds, N. A. Rayner, T. M. Smith, D. C. Stokes, and W. Wang, "An improved in situ and satellite SST analysis for climate," Journal of Climate, vol. 15, no. 13, pp. 1609-1625, 2002.

[140] B. N. Holben, T. F. Eck, I. Slutsker et al., "AERONET-a federated instrument network and data archive for aerosol characterization," Remote Sensing of Environment, vol. 66, no. 1, pp. 1-16, 1998. 
[141] O. Dubovik, M. Herman, A. Holdak et al., "Statistically optimized inversion algorithm for enhanced retrieval of aerosol properties from spectral multi-angle polarimetric satellite observations," Atmospheric Measurement Techniques, vol. 4, no. 5, pp. 975-1018, 2011.

[142] D. J. Diner, G. P. Asner, R. Davies et al., "New directions in earth observing: scientific applications of multiangle remote sensing," Bulletin of the American Meteorological Society, vol. 80, no. 11, pp. 2209-2228, 1999.

[143] J. V. Martonchik, D. J. Diner, R. A. Kahn et al., “Techniques for the retrieval of aerosol properties over land and ocean using multiangle imaging," IEEE Transactions on Geoscience and Remote Sensing, vol. 36, no. 4, pp. 1212-1227, 1998.

[144] J. V. Martonchik, D. J. Diner, K. A. Crean, and M. A. Bull, "Regional aerosol retrieval results from MISR," IEEE Transactions on Geoscience and Remote Sensing, vol. 40, no. 7, pp. 15201531, 2002.

[145] O. V. Kalashnikova and R. Kahn, "Ability of multiangle remote sensing observations to identify and distinguish mineral dust types: 2. Sensitivity over dark water," Journal of Geophysical Research D, vol. 111, no. 11, Article ID D11207, 2006.

[146] A. Sharma, V. Sivakumar, C. Bollig, C. Van Der Westhuizen, and D. Moema, "System description of the mobile LIDAR of the CSIR, South Africa," South African Journal of Science, vol. 105, no. 11-12, pp. 456-462, 2009.

[147] V. Sivakumar, M. Tesfaye, W. Alemu et al., "CSIR South Africa mobile LIDAR-first scientific results: comparison with satellite, sun photometer and model simulations," South African Journal of Science, vol. 105, no. 11-12, pp. 449-455, 2009.

[148] V. Sivakumar, M. Tesfaye, W. Alemu, A. Sharma, C. Bollig, and G. Mengistu, "Aerosol measurements over South Africa using LIDAR, Satellite and Sun Photometer," in Advances in Geosciences, 16, Atmospheric Science, chapter 22, pp. 253-262, World Scientific, 2010.

[149] M. Tesfaye, V. Sivakumar, J. Botai et al., "Retrieval of relative humidity from CSIR-NLC mobile LIDAR backscatter measurements," in Proceedings of the 25th Annual Conference of South African society for Atmosphere Science, September 2009.

[150] M. Tesfaye, V. Sivakumar, G. Mengistu et al., "Atmospheric Aerosol load morphological classification and retrieved visibility based on lidar backscatter measurement," in Proceedings of the 25th International Laser Radar Conference, pp. 487-490, Saint Pietersburg, Russia, 2010.

[151] J. R. Campbell, E. J. Welton, J. D. Spinhirne et al., "Micropulse lidar observations of tropospheric aerosols over northeastern South Africa during the ARREX and SAFARI 2000 dry season experiments," Journal of Geophysical Research D, vol. 108, no. 13, pp. 1-33, 2003.

[152] D. E. Terblanche, M. P. Mittermaier, S. J. Piketh, R. T. Bruintjes, and R. P. Burger, "The Aerosol Recirculation and Rainfall Experiment (ARREX): an initial study on aerosol-cloud interactions over South Africa," South African Journal of Science, vol. 96, no. 1, pp. 15-21, 2000.

[153] G.-J. Roelofs, H. Ten Brink, A. Kiendler-Scharr et al., "Evaluation of simulated aerosol properties with the aerosol-climate model ECHAM5-HAM using observations from the IMPACT field campaign," Atmospheric Chemistry and Physics, vol. 10, no. 16, pp. 7709-7722, 2010.

[154] V. Ramanathan and M. V. Ramana, "Persistent, widespread, and strongly absorbing haze over the Himalayan foothills and the Indo-Gangetic Plains," Pure and Applied Geophysics, vol. 162, no. 8-9, pp. 1609-1626, 2005.
[155] P. Ginoux, M. Chin, I. Tegen et al., "Sources and distributions of dust aerosols simulated with the GOCART model," Journal of Geophysical Research D, vol. 106, no. 17, pp. 20255-20273, 2001.

[156] T. Y. Tanaka and M. Chiba, "A numerical study of the contributions of dust source regions to the global dust budget," Global and Planetary Change, vol. 52, no. 1-4, pp. 88-104, 2006.

[157] X. Yue, H. Wang, H. Liao, and K. Fan, "Simulation of dust aerosol radiative feedback using the GMOD: 2. Dust-climate interactions," Journal of Geophysical Research D, vol. 115, no. 4, Article ID D04201, 2010.

[158] E. M. Wilcox and V. Ramanathan, "The impact of observed precipitation upon the transport of aerosols from South Asia," Tellus, Series B, vol. 56, no. 5, pp. 435-450, 2004.

[159] Z. Shi, M. D. Krom, T. D. Jickells et al., "Impacts on iron solubility in the mineral dust by processes in the source region and the atmosphere: a review," Aeolian Research, vol. 5, pp. 2142, 2012.

[160] A. Bhattachan, P. Dodorico, M. C. Baddock, T. M. Zobeck, G. S. Okin, and N. Cassar, "The Southern Kalahari: a potential new dust source in the Southern Hemisphere?" Environmental Research Letters, vol. 7, no. 2, Article ID 024001, 2012.

[161] Y. J. Kaufman, D. Tanré, O. Dubovik, A. Karnieli, and L. A. Remer, "Absorption of sunlight by dust as inferred from satellite and ground-based remote sensing," Geophysical Research Letters, vol. 28, no. 8, pp. 1479-1482, 2001.

[162] I. Tegen and I. Fung, "Contribution to the atmospheric mineral aerosol load from land surface modification," Journal of Geophysical Research, vol. 100, no. 9, pp. 18-726, 1995.

[163] M. T. Freiman and S. J. Piketh, "Air transport into and out of the industrial Highveld region of South Africa," Journal of Applied Meteorology, vol. 42, no. 7994, 1002 pages, 2003.

[164] Y. Wang, L. R. Leung, J. L. McGregor et al., "Regional climate modeling: progress, challenges, and prospects," Journal of the Meteorological Society of Japan, vol. 82, no. 6, pp. 1599-1628, 2004.

[165] J. Heintzenberg and R. J. Charlson, Clouds in the Perturbed Climate System, MIT Press, Cambridge, Mass, USA, 2009. 

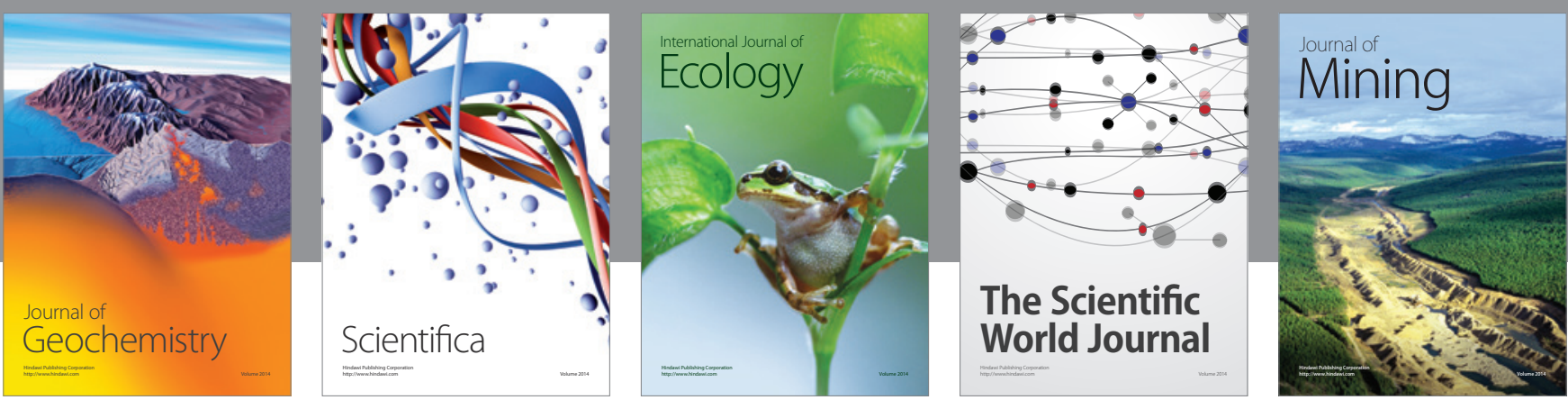

The Scientific World Journal
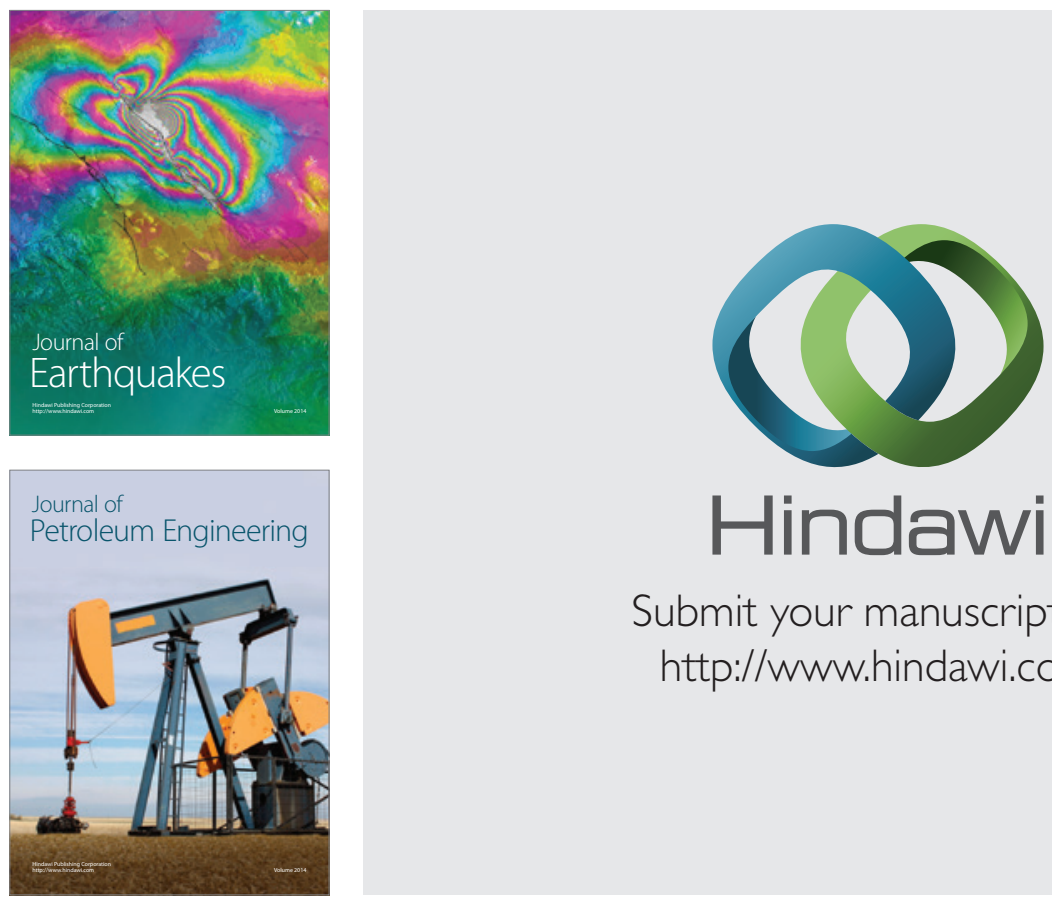

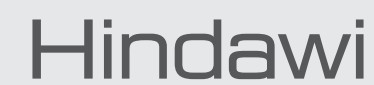

Submit your manuscripts at

http://www.hindawi.com
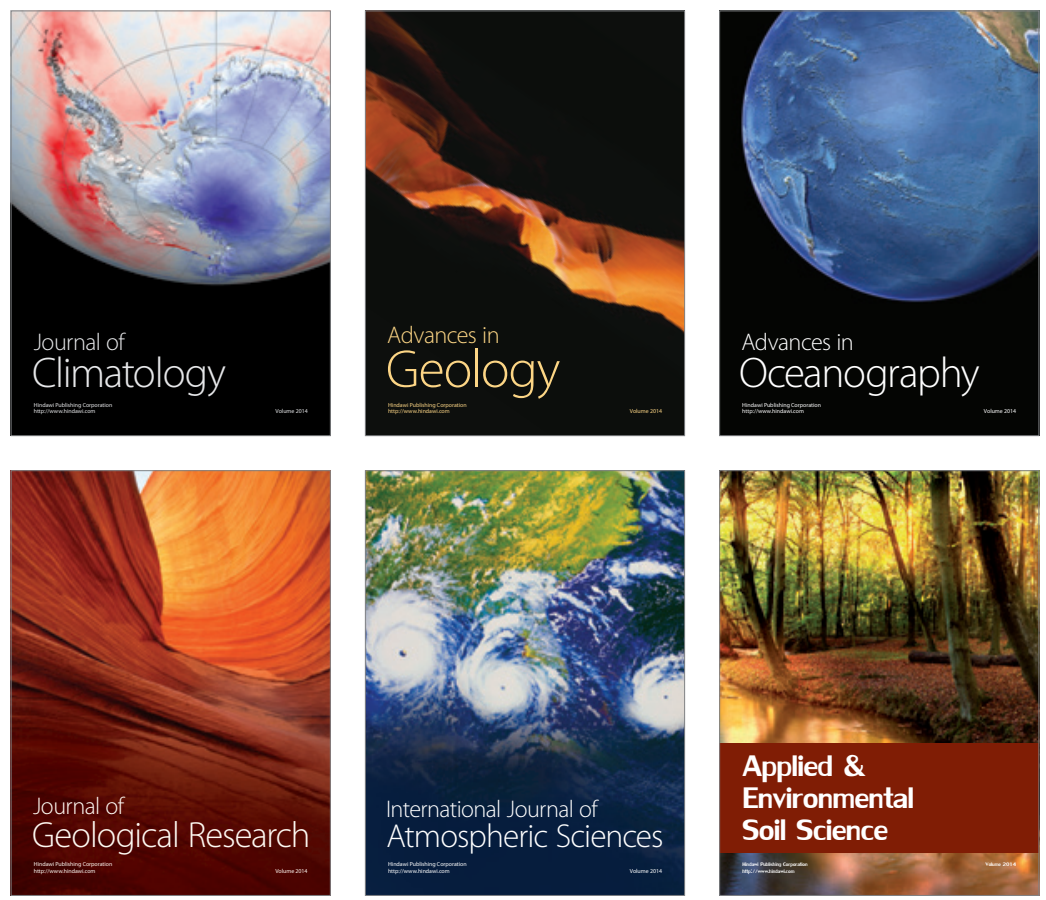
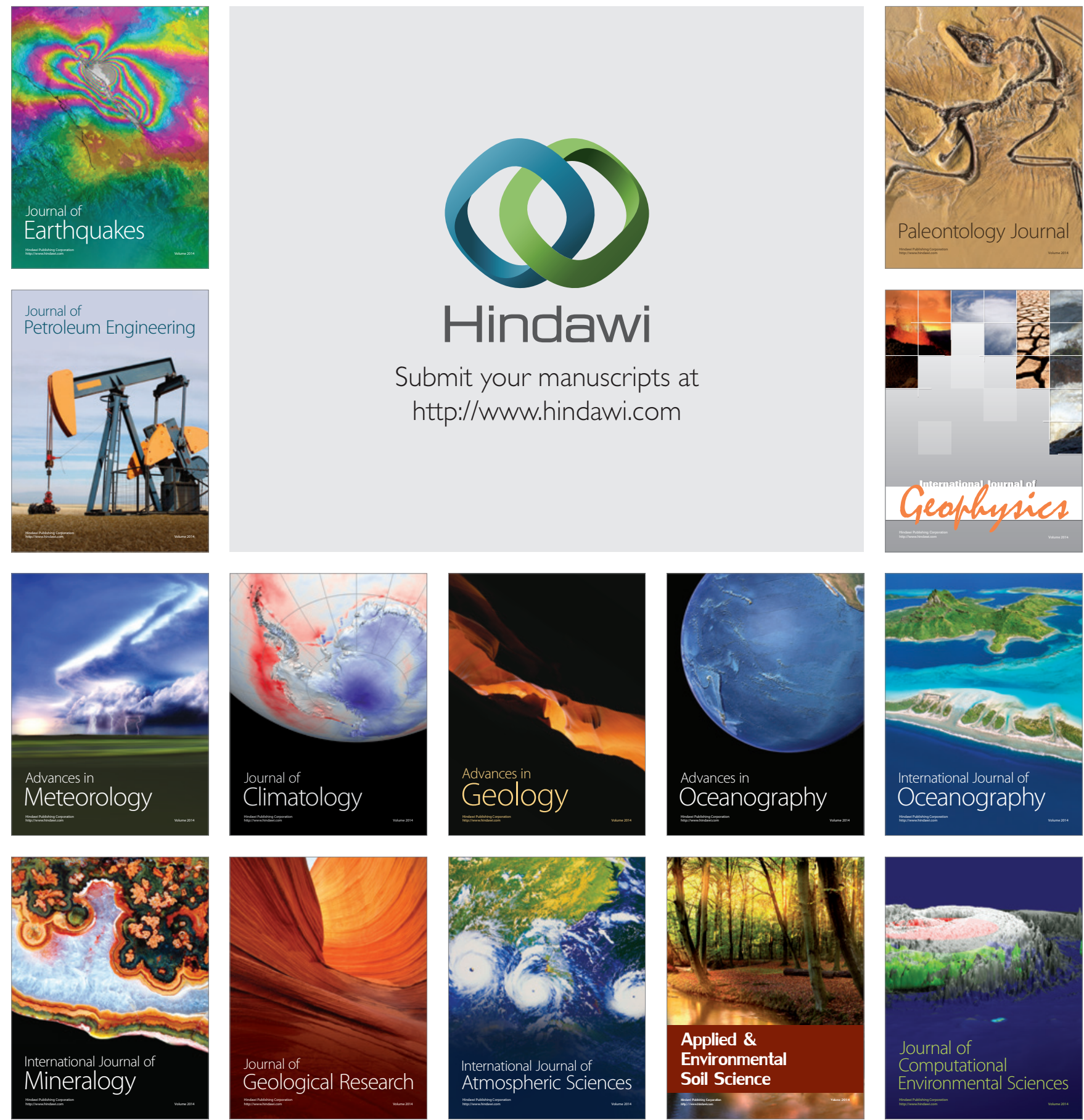